\title{
A quarter century of Culture's Consequences: a review of empirical research incorporating Hofstede's cultural values framework
}

Bradley L. Kirkman ${ }^{1}$, Kevin B. Lowe ${ }^{2}$ and Cristina B. Gibson ${ }^{3}$

\footnotetext{
${ }^{1}$ Department of Management, Mays Business School, Texas A\&M University, College Station, TX, USA; ${ }^{2}$ Department of Business Administration, Joseph M. Bryan School of Business and Economics, University of North Carolina at Greensboro, Greensboro, North Carolina, USA; ${ }^{3}$ Graduate School of Management, University of California, Irvine, California, USA
}

Correspondence:

Bradley L Kirkman, Department of Management, Mays Business School, Texas A\&M University, 4221 TAMU, College Station, TX 77843-4221, USA.

Tel: + 19798458813 ;

Fax: + 1979845 9641;

E-mail: brad.kirkman@tamu.edu

\begin{abstract}
Since Geert Hofstede's Culture's Consequences: International Differences in WorkRelated Values (Sage, 1980) was published, researchers have utilized Hofstede's cultural values framework in a wide variety of empirical studies. We review 180 studies published in 40 business and psychology journals and two international annual volumes between 1980 and June 2002 to consolidate what is empirically verifiable about Hofstede's cultural values framework. We discuss limitations in the Hofstede-inspired research and make recommendations for researchers who use Hofstede's framework in the future.
\end{abstract} Journal of International Business Studies (2006) 37, 285-320. doi: 10.1 057/palgrave.jibs.8400202

Keywords: Hofstede; cultural values; cross-cultural management

\section{Introduction}

Research using a variety of frameworks has shown that national cultural values are related to workplace behaviors, attitudes and other organizational outcomes (e.g., Kluckhohn and Strodtbeck, 1961; Hall, 1976; Hofstede, 1980a; Trompenaars, 1993; Schwartz, 1994; Ronen and Shenkar, 1985). Perhaps the most influential of cultural classifications is that of Geert Hofstede. Over two decades have passed since the publication of Culture's Consequences: International Differences in Work-Related Values (Hofstede, 1980a), inspiring thousands of empirical studies; however, a comprehensive review of the impact of Hofstede's framework is lacking. ${ }^{1}$ To fill this gap, we summarize and synthesize empirical research published between January 1980 and June 2002 that has applied Hofstede's framework to organizations. We focus on Hofstede's framework rather than others, given evidence that it has had far greater impact (Sivakumar and Nakata, 2001). For example, the Social Science Citations Index indicates that Hofstede's work is more widely cited than others (cited 1,800 times through 1999; Hofstede, 2001). Trompenaars (1993, iii), who has a competing framework, credits Hofstede 'for opening management's eyes to the importance of the [cross-cultural management] subject'. Our purpose is both to summarize existing research and to direct and inform future research, rather than provide an in-depth discussion of Hofstede's original study, a critique (e.g., Schwartz, 1994; Smith and Bond, 1999; McSweeney, 2002; Smith, 2002), or a replication
Received: 22 August 2002

Revised: 8 May 2005

Accepted: 17 May 2005

Online publication date: 4 May 2006 
(e.g., Punnett and Withane (1990); Shackleton and Ali, 1990; Merritt, 2000; Spector et al., 2001a).

We focus on aspects of Hofstede's work not discussed in recent reviews and meta-analyses. For example, most researchers focused exclusively on individualism-collectivism (IND-COL) at the individual level of analysis (e.g., Triandis, 1995; Earley and Gibson, 1998; Oyserman et al., 2002). Consequently, their implications and conclusions are based on a much narrower band of Hofstedeinspired research. Hofstede (2001) recently reviewed hundreds of studies published since his original book appeared in 1980. However, consistent with his opposition to applying the framework to the individual level, Hofstede 'ignores everything... but the culture level comparisons' (Smith, 2002, 123), thus missing an opportunity to draw conclusions across levels. Indeed, an analysis of references reveals very little overlap between studies we reviewed and those contained in previous reviews. Therefore our conclusions and implications should add value beyond previous reviews, as our purpose was to review studies at different levels of analysis and direction of effects to comprehensively integrate and synthesize the findings for all five cultural value dimensions in Hofstede's framework. As we shall show, without such a comprehensive review, much of the Hofstede-inspired research has remained fragmented and in some cases redundant, and researchers are unable to benefit from the cumulative knowledge that accrues from an integrated body of quality research. First, we provide a brief overview of Hofstede's cultural value dimensions and how they were derived, and then we discuss our typology and the rationale for including/excluding articles. Next, we review findings, research accomplishments and challenges within each major domain of our typology. Finally, we provide direction for future Hofstede-inspired research.

\section{An overview of Hofstede's cultural value dimensions}

Hofstede (1980a, 25) defined culture as 'the collective programming of the mind which distinguishes the members of one human group from another'. His framework was developed using data from over 116,000 morale surveys from over 88,000 employees from 72 countries (reduced to 40 countries that had more than 50 responses each) in 20 languages at IBM between 1967 and 1969 and again between 1971 and 1973. He later expanded the database with 10 additional countries and three regions (i.e.,
Arab countries and East and West Africa). Based on a country level factor analysis, he classified the original 40 countries along four dimensions. The first is IND-COL, with IND defined as 'a loosely knit social framework in which people are supposed to take care of themselves and of their immediate families only', while COL 'is characterized by a tight social framework in which people distinguish between ingroups and outgroups, they expect their ingroup to look after them, and in exchange for that they feel they owe absolute loyalty to it'(Hofstede, 1980b, 45). The second dimension is power distance (PD), defined as the extent to which a society accepts the fact that power in institutions and organizations is distributed unequally' (1980b, 45 ). Third, uncertainty avoidance (UA) is defined as 'the extent to which a society feels threatened by uncertain and ambiguous situations and tries to avoid these situations by providing greater career stability, establishing more formal rules, not tolerating deviant ideas and behaviors, and believing in absolute truths and the attainment of expertise' $(1980 b, 45)$. The fourth dimension is masculinity (MAS)-femininity (FEM), with MAS defined as 'the extent to which the dominant values in society are "masculine" - that is, assertiveness, the acquisition of money and things, and not caring for others, the quality of life, or people' $(1980 \mathrm{~b}, 46)$ and FEM defined as the opposite of MAS. Michael Harris Bond (Chinese Culture Connection, 1987) and later Hofstede and Bond (1988) developed a fifth dimension, Confucian dynamism (or long-term vs short-term orientation). Long-term orientation refers to future-oriented values such as persistence and thrift, whereas short-term orientation refers to past- and present-oriented values such as respect for tradition and fulfilling social obligations.

Hofstede's (1980a) work has been criticized for: reducing culture to an overly simplistic four or five dimension conceptualization; limiting the sample to a single multinational corporation; failing to capture the malleability of culture over time; and ignoring within-country cultural heterogeneity (Sivakumar and Nakata, 2001). In spite of criticism, researchers have favored this five-dimension framework because of its clarity, parsimony, and resonance with managers. Yet, even given the proliferation of studies incorporating the framework, there have been few attempts to summarize the empirical findings it has generated. Thus, a pressing and practical need in the literature at this time is a comprehensive review and discussion of ways to improve the use of Hofstede's framework. 


\section{Criteria used to select articles and organize the review}

We examine empirical research that assessed any of the five cultural values published in top-tier management and applied psychology journals (Extejt and Smith, 1990; Gomez-Mejia and Balkin, 1992; Johnson and Podsakoff, 1994; Tahai and Meyer, 1999) and in journals specializing in international management and psychology (see Table 1). We excluded areas such as marketing or finance because of the traditional delineation of these fields (in business schools and most academic journals) and the need to place limits on our comprehensiveness. We conducted article title, abstract, and methodology section searches from January 1980 to June 2002. We first conducted computer-assisted searches (e.g., ABI-Inform, Ebsco Host Academic Full-Text Elite) when full text was available; otherwise, each journal was physically searched. We then conducted computer-assisted keyword searches within journals using variations on Hofstede's terms (e.g., COL, collectivists, collectivistic). We included articles only if the authors empirically assessed the cultural values using either primary or secondary data. Primary data include research that assessed values through surveys, experiments, or other direct methods. Secondary data include research that used Hofstede's country scores to, for example, create cultural distance measures (Kogut and Singh, 1988). We also included a few studies that used country scores to assign cultural values to individuals (e.g., Bochner and Hesketh, 1994; Palich et al., 1995). A detailed analysis of the shortcomings of this particular method appears in our discussion. We mention these limitations here to warn readers about the variance in the quality of methodologies used in the studies we review. Previous reviews of the IND-COL literature have discussed the difficulty of comparing studies that used a wide variety of different measures and methods to operationalize cultural values (Earley and Gibson, 1998; Oyserman et al., 2002). Thus, comparing means directly across studies may be problematic. Space prohibits a critique of methodology for each of the studies, but readers should note that authors took different degrees of care to control for methodological concerns such as response bias or halo effects. Thus, as we note throughout, caution should be exercised in interpreting the findings. ${ }^{2}$

To organize the review, we used a two-tier classification scheme. The first tier pertained to the role of cultural values in the relationships
Table 1 Journals searched, with corresponding number of articles found

\begin{tabular}{|c|c|}
\hline Journal name & Number \\
\hline Academy of Management Journal & 22 \\
\hline Administrative Science Quarterly & 7 \\
\hline Advances in Global Leadership & 1 \\
\hline Advances in International Comparative Management & 1 \\
\hline Annual Review of Psychology & 0 \\
\hline British Journal of Psychology & 0 \\
\hline British Journal of Social Psychology & 2 \\
\hline European Journal of Social Psychology & 1 \\
\hline Group and Organization Management & 1 \\
\hline Human Relations & 2 \\
\hline International Journal of Commerce and Management & 2 \\
\hline International Journal of Comparative Sociology & 0 \\
\hline International Journal of Conflict Management & 1 \\
\hline International Journal of Intercultural Relations & 5 \\
\hline International Journal of Organizational Analysis & 2 \\
\hline International Journal of Psychology & 2 \\
\hline International Studies of Management and Organization & 1 \\
\hline Journal of Applied Behavioral Science & 1 \\
\hline Journal of Applied Psychology & 7 \\
\hline Journal of Applied Social Psychology & 3 \\
\hline Journal of Cross-Cultural Psychology & 16 \\
\hline Journal of Experimental Social Psychology & 1 \\
\hline Journal of International Business Studies & 41 \\
\hline Journal of International Management & 5 \\
\hline Journal of Management & 9 \\
\hline Journal of Management Studies & 0 \\
\hline Journal of Organizational Behavior & 6 \\
\hline Journal of Personality & 0 \\
\hline Journal of Personality and Social Psychology & 11 \\
\hline Journal of Research in Personality & 1 \\
\hline Journal of World Business & 1 \\
\hline Leadership Quarterly & 1 \\
\hline Management International Review & 6 \\
\hline Management Science & 1 \\
\hline Multinational Business Review & 2 \\
\hline Organization Science & 0 \\
\hline Organizational Behavior and Human Decision Processes & 4 \\
\hline Personnel Psychology & 2 \\
\hline Psychological Bulletin & 0 \\
\hline Psychological Review & 0 \\
\hline Small Group Research & 1 \\
\hline Strategic Management Journal & 11 \\
\hline Total & 180 \\
\hline
\end{tabular}

investigated. Research on culture has examined main associations between values and outcomes, as well as cultural values as moderators. Main effect studies have been labeled 'Type I' and moderator studies 'Type II' (Lytle et al., 1995). Our second classification was by level of analysis, whether individual, group/organizational, or country. In 
spite of Hofstede's (1980a, 2001) argument against using his dimensions for purposes other than country level studies, we found that a majority of researchers had adapted them for use at the individual or group/organization levels. All of these levels are valid, depending on the research question and on whether there is more commonality within, than between groups (Sivakumar and Nakata, 2001). Thus, we argue that excluding these studies would create an incomplete picture of Hofstede's impact. In addition, analyses of the same data at different levels of analysis do not necessarily lead to equivalent findings or replication of dimensions (Leung and Bond, 1989; Hofstede et al., 1993, 2001). To accurately sort the studies into the proper level of analysis, we scrutinized each study's theory and method section to determine the level at which the study was conceptualized and analyzed, respectively. The level at which the data were collected was not always as informative. For example, studies using individual level survey data could be classified as individual, group/organizational, or country level. For individual level studies, data must have been collected and analyzed at the individual level of analysis and tied to individual level outcomes. For group/organizational, the data had to be aggregated to the group or organizational level and linked to group/organizational outcomes. For country level studies, either individual level data had to be aggregated by country and linked to country level outcomes or pre-existing country level measures (such as Hofstede's, 1980a country level scores) had to be used. Table 2 depicts our $2 \times 3$ classification with the corresponding number of articles reviewed within each of the six cells. To ease interpretation, we further organize findings by topic using subject matter headings from business and psychology. To facilitate reader comparisons of topics at respective levels, Table 3 shows the topics on the vertical axis and the level of analysis on the horizontal. Also, Supplementary Appendices A and B contain detailed article summaries on culture as main and moderator effects, respectively, for all 180 articles in our review. ${ }^{3}$

\section{Research incorporating Hofstede's cultural value dimensions}

We first review culture as a main effect (i.e., Type I studies) at the individual level of analysis, and then at the group/organization and country levels. We then review findings that incorporate culture as a moderator (i.e., Type II studies) at these levels of analysis. When a study included multiple levels or type of effect, we discuss each finding in the appropriate section and note cross-listings.

\section{Type I studies of culture at the individual level of analysis}

Our review uncovered two basic types of Type I individual level study: cross-cultural and monocultural. In both types of study, researchers typically examine relationships between individuals' cultural values and various outcomes; however, in cross-cultural studies two or more countries are normally included, whereas in mono-cultural studies all individuals emanate from the same country. Researchers have shown that there is plenty of within-country variation on cultural values (Hofstede, 1980a; Au, 1999). Clearly, 'people vary on pivotal psychological dimensions (e.g., PD beliefs, traditionality) both on a between-country basis and on a within-country basis' (Brockner, 2005: 355). Thus, even though mono-cultural studies may not be viewed as technically crosscultural, we still include those studies empirically assessing cultural values in only a single country because of the theoretical importance of understanding within country cultural variation. Cultural values were associated with outcomes in management and applied psychology domains, including: change management; conflict management; decision-making; human resource management (HRM); leadership; organizational citizenship behavior (OCB); work-related attitudes; negotiation behavior; reward allocation; and individual behavior relating to group processes and personality.

\section{Change management (4)}

Collectivists in the US showed more positive group attitudes toward a new technology and had better

Table 2 Classification scheme used for literature review and number of articles included

\begin{tabular}{lcrr}
\hline & Individual level & Group/organization level & Country level \\
\hline Culture as a main effect & 64 & 6 & 78 \\
Culture as a moderator & 23 & 5 & 4 \\
Total & 87 & 11 & 32 \\
\hline
\end{tabular}

Note: If a study was listed in more than one section, it was counted only once in the section in which it first appeared. 
Table 3 Research subject matter by level of analysis

\begin{tabular}{|c|c|c|c|}
\hline & Individual & Group/organization & Country \\
\hline Change management & $\begin{array}{l}\text { James }(1993)^{\text {main }}, \text { Geletkanycz } \\
(1997)^{\text {main }}, \text { Anakwe et al. } \\
(1999)^{\text {main }}, \text { Eby et al. }(2000)^{\text {main }}\end{array}$ & & \\
\hline Conflict management & $\begin{array}{l}\text { Leung }(1987)^{\text {main }}, \text { Leung } \\
(1988)^{\text {main }}, \text { Cocroft and } \\
\text { Ting-Toomey }(1994)^{\text {main }} \text { ', } \\
\text { Gabrielidis et al. }(1997)^{\text {main }}\end{array}$ & $\begin{array}{l}\text { Elron }(1997)^{\text {main }} \\
\text { Oeztzel }(1998)^{\text {main }}\end{array}$ & Smith et al. $(1998)^{\text {main }}$ \\
\hline Decision-making & $\begin{array}{l}\text { Ali }(1993)^{\text {main }}, \text { Nooteboom et al. } \\
(1997)^{\text {main }}{ }^{\text {, Mitchell et al. }} \\
(2000)^{\text {main }}, \text { Steensma et al. } \\
(2000 a)^{\text {main }}\end{array}$ & & \\
\hline $\begin{array}{l}\text { Human resource } \\
\text { management }\end{array}$ & $\begin{array}{l}\text { Ozawa et al. }(1996)^{\text {main }}, \text { Cable and } \\
\text { Judge }(1994)^{\text {main }}, \text { Ramamoorthy } \\
\text { and Carroll }(1998)^{\text {main }}, \text { Earley } \\
(1986)^{\text {main }} \text {, Earley et al. (1999) }\end{array}$ & & $\begin{array}{l}\text { Newman and Nollen }(1996)^{\text {main }} \text {, } \\
\text { Roth and O'Donnell }(1996)^{\text {main }}, \\
\text { Schuler and Rogovsky }(1998)^{\text {main }}, \\
\text { Ryan et al. (1999) }\end{array}$ \\
\hline Leadership & $\begin{array}{l}\text { Casimir and Keats }(1996)^{\text {main }} \\
\text { Pillai and Meindl }(1998)^{\text {main }}, \\
\text { Helgstrand and Stuhlmacher } \\
(1999)^{\text {main }} \text {, Jung and Avolio } \\
(1999)^{\text {mod }} \text {, Chan and } \\
\text { Drasgow }(2001)^{\text {main }}\end{array}$ & Pillai and Meindl (1998) & $\begin{array}{l}\text { Shenkar and Zeira }(1992)^{\text {main }} \\
\text { Offerman and Hellmann } \\
(1997)^{\text {main }}, \text { House et al. (1999) }\end{array}$ \\
\hline OCB & $\begin{array}{l}\text { Moorman and Blakely }(1995)^{\text {main }} \\
\text { Van Dyne et al. }(2000)^{\text {main }}\end{array}$ & & \\
\hline Work-related attitudes & $\begin{array}{l}\text { Bochner and Hesketh }(1994)^{\text {main }}, \\
\text { Palich et al. }(1995)^{\text {mod }}, \text { Bennett } \\
(1999)^{\text {main }}, \text { Chiu }(1999)^{\text {main }}, \\
\text { Clugston et al. }(2000)^{\text {main }}, \text { Feldman } \\
\text { and Bolino }(2000)^{\text {main }}, \text { Lee et al. } \\
(2000 a)^{\text {main }} \text {, Lee et al. }(2000 b)^{\text {mod, }}, \\
\text { Martella and Maass }(2000)^{\text {mod }}, \\
\text { Schaubroeck et al. }(2000)^{\text {mod, }} \\
\text { Vandenberghe et al. }(2001)^{\text {mod, }} \\
\text { Harpaz et al. }(2002)^{\text {main }}, \\
\text { Thomas and } \\
\text { Au (2002) }\end{array}$ & & 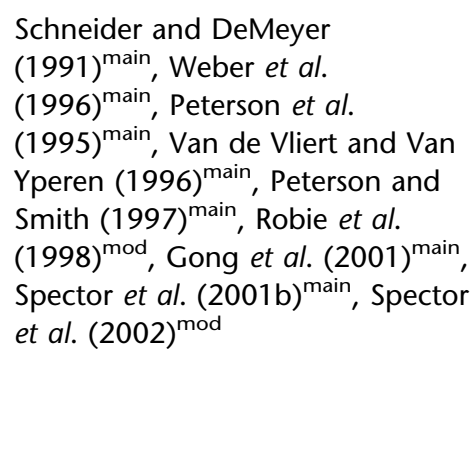 \\
\hline Negotiation & 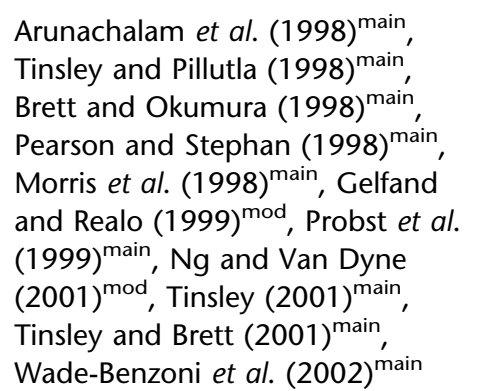 & & \\
\hline
\end{tabular}


Table 3 Continued

\begin{tabular}{ll}
\hline Individual \\
\hline Reward allocation & Mann et al. $(1985)^{\text {main }}$, Leung and \\
& Iwawaki $(1988)^{\text {main }}$, Hui et al. \\
& $(1991)^{\text {main }}$, Tower et al. (1997) \\
& Chen et al. $(1997)^{\text {main }}$, C.C. Chen \\
& et al. $(1998 a, b)^{\text {main }}$, McLean-Parks \\
& et al. $(1999)^{\text {main }}$, Gomez et al. \\
& $(2000)^{\text {main }}$
\end{tabular}

Behavior relating to group processes and personality

Entrepreneurship

Social networks

Entry modes
Triandis et al. (1988) ${ }^{\text {main }}$, Earley $(1989)^{\mathrm{mod}}$, Hui and Villareal $(1989)^{\text {main }}$, Earley $(1993)^{\mathrm{mod}}$, Oyserman (1993) ${ }^{\text {main }}$, Wagner $(1995)^{\mathrm{mod}}$, Yamaguchi et al. $(1995)^{\text {main }}$, Eby and Dobbins $(1997)^{\text {main }}$, Kwan et al. $(1997)^{\text {main }}$, Wojciszke $(1997)^{\text {main }}$, Chen et al. $(1998 \mathrm{a}, \mathrm{b})^{\mathrm{mod}}$, Oyserman et al. (1998) ${ }^{\text {main }}$, Grimm et al. (1999) ${ }^{\text {main }}$, Tafarodi et al. $(1999)^{\text {main }}$, Thomas (1999) ${ }^{\text {main }}$ Kirkman and Shapiro (2000) ${ }^{\text {main, }}$ Satterwhite et al. (2000) ${ }^{\text {main, }}$, Carpenter and Radhakrishnan $(2000)^{\text {main }}$, Gibson and ZellmerBruhn (2001) ${ }^{\text {main }}$, Kirkman and Shapiro (2001a) main
Chatman and Barsade $(1995)^{\mathrm{mod}}$, Chatman et al. (1998) ${ }^{\mathrm{mod}}$,

Cox et al. (1991) ${ }^{\text {main, }}$

Erez and Somech (1996) ${ }^{\mathrm{mod}}$,

Eby and Dobbins (1997) ${ }^{\text {main }}$,

Earley $(1999)^{\mathrm{mod}}$,

Gibson (1999) mod,

Kirkman and Shapiro (2001b) ${ }^{\text {main }}$,

Lam et al. (2002a) $)^{\text {mod }}$
Krug and Nigh (1998) ${ }^{\text {main }}$ Oyserman et al. (2002) main
Morris et al. (1993) ${ }^{\text {main }}$, Morris et al. (1994) main
Country

Group/organization Country


Table 3 Continued

\begin{tabular}{ccc}
\hline Individual Country & Group/organization
\end{tabular}

Foreign direct

investment

Joint venture

characteristics and

performance

Alliance formation

Dickson and Weaver (1997) $)^{\text {mod }}$

Innovation and

research and

development

Societal outcomes

(e.g., wealth, national accounting systems, number of intellectual property violations

Motivation

Organizational justice Lind et al. (1997) ${ }^{\mathrm{mod}}$, Au et al.

Erez and Earley (1987) ${ }^{\mathrm{mod}}$,

Dorfman and Howell (1988) ${ }^{\mathrm{mod}}$,

Earley $(1994)^{\mathrm{mod}}$, Eylon and $\mathrm{Au}$

$(1999)^{\mathrm{mod}}$, Lam et al. $(2002 \mathrm{a})^{\mathrm{mod}}$ $(2002)^{\mathrm{mod}}$, Brockner et al.

$(2000)^{\mathrm{mod}}$, Brockner et al.

$(2001)^{\mathrm{mod}}$, Lam et al. $(2002 \mathrm{~b})^{\mathrm{mod}}$
Benito and Gripsrud (1992) ${ }^{\text {main }}$,

$\mathrm{Li}$ and Guisinger (1992) ${ }^{\text {main }}$, Loree and Guisinger (1995) ${ }^{\text {main }}$, Kallunki et al. (2001) ${ }^{\text {main }}$, Thomas and Grosse (2001) ${ }^{\text {main }}$, Habib and Zurawicki (2002) ${ }^{\text {main }}$

Li and Guisinger (1991) ${ }^{\text {main }}$, Datta and Puia (1995) ${ }^{\text {main }}$, Barkema et al. (1996) $^{\text {main }}$, Barkema et al. ${(1997)^{\text {main }}}$, Barkema and Vermeulen (1997) ${ }^{\text {main }}$,

Gomez-Mejia and Palich $(1997)^{\text {main }}$, Park and Ungson $(1997)^{\text {main }}$, Morosini et al. $(1998)^{\text {main }}$, Glaister and Buckley $(1999)^{\text {main }}$, Luo and Peng (1999) $^{\text {main }}$, Merchant and Schendel $(2000)^{\text {main }}$, Hakanson and Nobel (2001) ${ }^{\text {main }}$, Luo $(2001 \mathrm{a})^{\text {main }}$, Luo (2001b) ${ }^{\text {main }}$, Luo and Park (2001) ${ }^{\text {main }}$, Luo et al. $(2001)^{\mathrm{mod}}$, Reuer (2001) $)^{\text {main }}$, Luo (2002) ${ }^{\text {main }}$, Pothukuchi et al. $(2002)^{\text {main }}$

Kashlak et al. (1998) ${ }^{\text {main }}$, Steensma et al. (2000b) ${ }^{\text {main,mod }}$

Shane $(1995)^{\text {main }}$, Shane et al. $(1995)^{\text {main }}$, Jones and Teegen $(2001)^{\text {main }}$, Richards and De Carolis $(2003)^{\text {main }}$

Franke et al. $(1991)^{\text {main }}$, Diener and Diener (1995) ${ }^{\text {main,mod }}$, Diener et al. (1995) $^{\text {main }}$, Diener et al. (2000) $)^{\text {mod, }}$ Salter and Niswander (1995) ${ }^{\text {main }}$, Riahi-Belkaoui (1998) ${ }^{\text {main }}$, Husted $(1999)^{\text {main }}$, Ronkainen and Guerrero-Cusumano (2001) ${ }^{\text {main }}$

main, main effect study; mod, moderating effect study.

retention when a technology presentation contained a group-relevance theme (the same was true for individualists when the presentation contained a strong self-relevance theme) (James, 1993). COL was negatively related to receptivity to distance learning technology (Anakwe et al., 1999), and was positively related to perceptions of an organization's readiness to change to team-based selling (Eby et al., 2000) in the US. Using Hofstede's (1980a) country scores to assign cultural values to 
managers in 20 countries, Geletkanycz (1997) found that managers were more likely to believe that the future chief executive officer (CEO) of their company should have the same expertise as the current CEO, and that the company's future corporate strategy should be the same as the existing corporate strategy (i.e., essentially demonstrating acceptance of the status quo) when they were high on IND, and low on UA, PD, and longterm orientation.

\section{Conflict management (4)}

Hong Kong (HK) subjects (who were significantly higher in COL) preferred bargaining and mediation more than US subjects in a scenario-based experiment with undergraduate and non-student subjects (Leung, 1987). In both countries, subjects' procedure preferences were related to the extent to which the procedure was perceived as favorable to the disputants, fair, capable of animosity reduction, and allowing process control. Leung (1988) found that HK subjects were more likely to sue a stranger than were US subjects; and COL was associated with higher likelihood of suing when the dispute was between strangers (but not friends). US students (who scored significantly lower on both IND and COL; see our discussion section for debate on IND-COL as unipolar or bipolar at the individual level) used more antisocial, self-attribution, hint, and self-presentation strategies than Japanese subjects, who used more indirect face strategies (Cocroft and Ting-Toomey, 1994). Finally, Mexican student subjects (who were significantly higher on COL and IND and lower on FEM than US subjects) showed more concern for others' outcomes in conflict resolution than US students (Gabrielidis et al., 1997). More specifically, Mexican scores on accommodation and collaboration were higher than those in the US.

\section{Decision-making (4)}

IND was positively related to consultative, participative, and autocratic decision-making styles and to attitudes toward risk in Saudi Arabian managers (Ali, 1993). Nooteboom et al. (1997) found that UA was negatively related to the probability of a potential loss by transaction partners, but unrelated to the size of loss among 97 firm-supplier alliances in the Netherlands. Mitchell et al. (2000), using Hofstede's (1980a) country scores at the individual level and assessing business professionals' cognitive scripts, found that IND and PD were positively related to 'ability' scripts (i.e., given resources, the person is able to carry out a goal); IND was positively related to 'willingness' scripts (i.e., given resources, the person will want to carry out a goal); and the relationship between 'arrangements' scripts (i.e., access to required materials) and starting a new business was stronger for individualists than for collectivists in the US, Mexico, China, Japan, and Chile. Using country scores, entrepreneurs from seven countries (Australia, Finland, Greece, Indonesia, Mexico, Norway, and Sweden) viewed cooperative strategies with other firms as more acceptable when they were lower in IND and MAS, but higher in UA (Steensma et al., 2000a). Those higher, rather than lower, in IND and UA preferred contractual safeguards more, and perceived partner commonality was positively linked to UA.

\section{HRM (5)}

US undergraduates, who were significantly higher on IND than Japanese (using Singelis et al.'s (1995) self-construal measure), perceived a change to an affirmative action program less favorably and fair than Japanese subjects (Ozawa et al., 1996). COL was negatively related to preferences for individualbased pay in the US (Cable and Judge, 1994) and to the use of selection tests, formal appraisal practices, and desire for promotions based on merit, and positively related to preference for equality-based rewards and employment security among US business undergraduates (Ramamoorthy and Carroll, 1998). Both COL and PD interacted with feedback type such that US subjects' performance increased as a result of both positive and negative feedback, but in England (where COL and IND were significantly higher), only positive feedback resulted in performance increases (Earley, 1986). In a second sample, the importance of feedback received and trust in supervisor partially mediated the main effects of praise, criticism, and culture on performance. In a sample of managers completing a managerial simulation in the US, Czech Republic and PRC (US subjects were significantly higher on IND than either Czech or PRC subjects who did not differ), Earley et al. (1999) found that individual feedback played a role for both individualists and collectivists, whereas group feedback was critical only for collectivists.

\section{Leadership (4)}

In a sample of Anglo- and Chinese-Australian managers, Casimir and Keats (1996) assessed preferences for leadership styles from among four choices (i.e., created by crossing the extent to 
which a leader is high or low on both concern for group performance and maintenance of group relations). Both cultures preferred leaders who expressed high concern for both performance and group relations, and did not differ significantly on IND-COL. In high-stress work environments, both cultures maintained their preference for highconcern leaders; however, in low-stress environments, Chinese respondents preferred a leader who showed concern for group relations equally to leaders high on both types of concern. In a second study, COL was positively related to the level of charismatic leadership, which in turn was positively related to supervisory ratings of work unit performance, job satisfaction, satisfaction with the leader, and leader effectiveness in over 100 work units of a US firm (Pillai and Meindl, 1998). Helgstrand and Stuhlmacher (1999) found that both Danish and US high school and undergraduate students rated leaders who were feminine and individualistic as most effective (Danes were lower on PD). Finally, using horizontal $(\mathrm{H})$ and vertical (V) aspects of IND and COL (i.e., VCOL represents a tendency to view the self as an aspect of the group, see members of an ingroup as different from the self, and accept inequality; HCOL represents the tendency to view the self as an aspect of the group, see members of an ingroup as similar to the self, and value equality; VIND represents the extent to which an individual's self-concept is autonomous but expects inequality; and HIND represents the extent to which an individual's self-concept is autonomous and the individual is seen as equal to others), Chan and Drasgow (2001) surveyed military recruits and junior college students in Singapore and the US to explore links between cultural values and various dimensions of motivation to lead (MTL). They found that HIND was negatively related to noncalculative MTL (i.e., people lead only when they are not calculative about the costs of leading relative to the benefits) and socialnormative MTL (i.e., people lead because they feel a sense of responsibility or duty); and VIND was positively related to affective identity MTL (i.e., some people just like to lead others) and socialnormative MTL, and negatively related to noncalculative MTL.

\section{$O C B(2)$}

In a sample of US financial services employees, COL (assessed using the values, norms, and beliefs dimensions of Wagner and Moch (1986)) was positively related to several dimensions of OCB after controlling for procedural justice (Moorman and Blakely, 1995). In a sample of cooperative housing residents in the US, COL was positively related to OCB, with organization-based self-esteem fully mediating the relationship (Van Dyne et al., 2000).

\section{Work-related attitudes (8)}

Bochner and Hesketh (1994) surveyed Australian bank employees representing 28 different nationalities, assigned each a country score for IND-COL and $\mathrm{PD}$, and placed them into high and low groups on the two values. Collectivists reported having more informal contact with fellow workers, knew staff better, and were more likely to work on a team than alone compared with individualists. Those high, rather than low, in PD were less open with their superiors, had more contact with them, described their supervision as being more close and direct, were more task-oriented, and had greater beliefs in Theory $X$ (i.e., a management style favoring centralized decision-making, tight control, and hierarchy). Bennett (1999), after first confirming that a US sample was significantly lower on COL and higher on MAS than a PRC sample, found that COL was positively related to favorable attitudes towards group activities and cooperation in both countries. MAS was negatively related to attitudes towards human development, but only in the US sample.

Chiu (1999) found that individualists scored higher on positive affect and job satisfaction and lower on work strain than collectivists in a sample of Singaporean and HK nurses, who were significantly higher on COL and lower on IND than Australian and US nurses. Clugston et al. (2000) assessed the relationships among Hofstede's four original cultural values and three bases (i.e., affective, continuance, and normative) and foci (i.e., organization, supervisor, and workgroup) of commitment using surveys in a US public agency. COL was positively related to affective commitment to supervisors and the workgroup, continuance commitment to the workgroup, and normative commitment to all foci; and PD was positively related to affective commitment to the organization and both continuance and normative commitment to all foci. Lee et al. (2000a) found that individualists were more attuned toward a promotion focus (i.e., the pursuit of gains and aspiration toward ideals), whereas collectivists were more attuned toward a prevention focus (i.e., the avoidance of losses, and the fulfillment of obliga- 
tions) in a sample of US undergraduate subjects who were significantly higher on IND (i.e., independent self-construal) and lower on COL (i.e., interdependent self-construal) than HK undergraduates. Harpaz et al. (2002) found that, over time, new work entrants from low UA countries (based on Hofstede's (1980a) country scores assigned to individuals) had increased work centrality. In a study of behavioral responses to job dissatisfaction in a sample of executive education participants in New Zealand and HK (New Zealanders were higher in HIND and VCOL than those in HK), Thomas and $\mathrm{Au}$ (2002) found that HIND was positively related to voice and that VCOL was positively related to neglect and negatively related to loyalty. Finally, cultural distance (based on the degree of difference between an individual and others in their context using country scores) was unrelated to opportunities to learn or further develop skills, internship satisfaction, or organizational commitment among a sample of US MBA students in overseas internships (Feldman and Bolino, 2000).

\section{Negotiation (9)}

HK negotiators (who scored significantly higher on COL and lower on IND than US negotiators) obtained higher joint outcomes than those in the US in a two-party negotiation experiment (Arunachalam et al., 1998). Negotiators with a high, rather than a low, best alternative to a negotiated agreement (BATNA) obtained larger outcomes in both HK and the US. Mediation was associated with higher joint outcomes and had a stronger effect in the US than in HK. In a similar experiment, Tinsley and Pillutla (1998) found that US subjects scored significantly higher on self-enhancement (i.e., a cultural value 'conceptually similar' to IND; $p$ 713) and lower on self-transcendence (i.e., a cultural value conceptually similar to $\mathrm{COL}$ ) than $\mathrm{HK}$ subjects using Schwartz's (1992) cultural value inventory. US subjects rated self-interested and joint problem-solving as more appropriate than their HK counterparts. Further, cooperative instructions were interpreted by US subjects as meaning they should strive for joint gain, whereas HK subjects interpreted them as meaning they should strive for equality. Finally, dyad sum was positively related to satisfaction for US (but not HK) subjects, whereas dyad difference was positively related to satisfaction for HK (but not US) subjects.

In a series of inter- and intra-cultural dyad experiments, Brett and Okumura (1998), after showing that US negotiators were more individua- listic but less hierarchical (i.e., lower in PD) than the Japanese, found that individualists endorsed self-interest in negotiations, and that negotiators with stronger hierarchical values endorsed distributive tactics and reported spending significantly more time discussing power. Brazilians (who scored significantly lower on IND than US subjects) preferred accommodation, collaboration, and withdrawal negotiating styles more, whereas US subjects preferred competition in student dyad negotiation experiments (Pearson and Stephan, 1998). US subjects preferred negotiation styles reflecting a high concern for self, whereas Brazilians preferred a style reflecting a high concern for others. Finally, Brazilians made accommodations and avoided conflict more when the conflict was with an ingroup, rather than an outgroup, member, whereas US subjects treated ingroup and outgroup members similarly. Importantly, results were replicated using IND-COL rather than country.

In a sample drawn from the US, the People's Republic of China (PRC), India, and the Philippines (with culture assessed using Schwartz's (1994) value inventory), Chinese managers preferred an avoiding style, with societal conservatism (i.e., low openness to change) fully mediating the effects of country on conflict style; and US managers preferred a competing style of conflict, with selfenhancement (i.e., IND) fully mediating the effects of country on conflict style (Morris et al., 1998). In a sample of US undergraduates, Probst et al. (1999) found type of prisoner's dilemma (i.e., single-group $v s$ intergroup) moderated the main effects that VIND and VCOL had with cooperation such that vertical individualists were least cooperative in the single-group prisoner's dilemma but were more cooperative in the intergroup dilemma (when cooperation with the group maximized personal outcomes). Vertical collectivists were most cooperative in the single-group dilemma but less in the intergroup dilemma (when group defection resulted in maximum group outcomes). Examining businesspeople from Japan, Germany, and the US, Tinsley (2001) showed that IND was positively related to using interest strategies and negatively related to using power strategies (Japanese respondents were significantly lower on IND than German or US respondents). Studying business students in HK and the US, Tinsley and Brett (2001) found that US students were more self-directed, less hierarchical, and less tradition-bound than HK students; US students placed greater emphasis on discussing interests and synthesizing multiple interests than 
did HK students; and American dyads were significantly more likely to reach an integrative outcome than were HK dyads. Finally, Wade-Benzoni et al. (2002) found that US MBAs (who were significantly higher on IND than Japanese undergraduates) were less cooperative, reached fewer equal solutions, and expected others to be less cooperative than the Japanese.

\section{Reward allocation (8)}

Assessing COL in both Japan and the US, Leung and Iwawaki (1988) found that the more collectivistic a subject, the more he or she followed the equality rule (everyone receives the same reward) and the less he or she followed the equity rule (rewards allocated based on effort). Contrary to expectations, Japanese and US subjects did not significantly differ on COL. After including South Korea in the dataset, for low input subjects (who participated infrequently), there were no differences across countries in the use of the equity norm, nor did they allocate more equally with friends (i.e., ingroups) and more equitably with strangers (i.e., outgroups). Generous allocators (i.e., low-input allocators using equity rules and high-input allocators using equality rules) were better liked (in all three countries) and rated as fairer than allocators who were less generous (findings held in Japan and the US, but not in South Korea). Hui et al. (1991) found that compared with US subjects, when resources were plentiful, HK subjects (who scored significantly higher on COL) put a greater emphasis on equal allocation of rewards; when the reward was fixed, HK subjects were more generous and treated close friends, compared with co-workers, more generously, whereas US subjects made no such distinction.

Primary school Japanese subjects (who scored significantly higher on COL) were more likely to follow 'equal-say' rules than Australian subjects, who tended to follow more 'self-interest' rules in a game experiment (Mann et al., 1985). In a study of British and Russian students (Tower et al., 1997), when British students (who scored significantly lower on COL) were low performers or allocating rewards with a co-worker who was a friend, they allocated more to themselves; and there were no allocation differences for the British when performance was high or when the co-worker was a stranger. In contrast, when Russian students were high performers or allocating rewards to a coworker who was a stranger, they allocated more reward to themselves; and there were no allocation differences for the Russians when performance was low or the co-worker was a friend.

VCOL was positively related to reward allocation reform in an in-basket exercise of managers in the PRC (Chen et al., 1997). In contrast, HCOL was marginally and negatively related to reward allocation reform. An interaction effect for VCOL and HCOL indicated that the negative relation between HCOL and support for reform holds only under the condition of low VCOL. VCOL was also negatively related to egalitarian allocation preferences, whereas HCOL was negatively related to differential allocation preferences. In a second study, Chen et al. (1998a) asked undergraduate students in HK and the US to make reward allocation decisions after reading a case-vignette. Reward allocation was more differential when task interdependence was low rather than high, and when the goal was productivity or fairness rather than solidarity in both countries. In the high interdependence situation, achievement motivation was negatively related to the differential allocation, but when it was low, achievement motivation was negatively related to differential allocation only for the HK subjects, but positively related for US subjects. COL was negatively related to differential allocation in HK but not the US. Individualistic MBA students in Singapore and the US took slightly more time to recover, and less time to allocate, resources than collectivists (McLean-Parks et al., 1999). In both cultures, equity rules were used more when distributing a resource, and equality when recovering resources. After showing that Mexican MBAs were significantly more collectivistic than US students, Gomez et al. (2000) found that collectivists gave more generous evaluations to ingroup, rather than outgroup, members in a teamwork scenario-based experiment. Individualists valued task inputs in determining evaluations more so than did collectivists, whereas both valued equity-based rewards.

\section{Individual behavior relating to group processes and personality (16)}

As some of these studies are only tangentially related to organizational contexts and are more social psychological in focus (e.g., Hui and Villareal, 1989; Oyserman, 1993; Yamaguchi et al., 1995; Kwan et al., 1997; Wojciszke, 1997; Oyserman et al., 1998; Grimm et al., 1999; Tafarodi et al., 1999; Carpenter and Radhakrishnan, 2000; Satterwhite et al., 2000), we highlight only those that have clear links to work-related outcomes. For example, Triandis et al. (1988) conducted three studies to 
examine the relationship between IND and COL and self-ingroup relations. Surveys responses from US undergraduates were factor-analyzed, and a multifaceted conceptualization of IND emerged. US respondents viewed competition as occurring between individuals, whereas Puerto Rican respondents viewed competition as occurring more between ingroups and outgroups, rather than within ingroups.

COL was positively related to positive assessments of group processes in a study of undergraduates from 14 countries studying in New Zealand (Thomas, 1999). Cultural distance on COL (i.e., how different, on average, each individual is from other group members) was negatively related to group receptiveness. In a sample of US undergraduates, COL was positively related to selfefficacy for teamwork, need for social approval, and positive past experience working in teams (Eby and Dobbins, 1997). In support of their theoretical model (Kirkman and Shapiro, 1997), Kirkman and Shapiro (2000) found that COL was positively related to receptivity to team-based rewards using employee surveys in a US insurance company. Using surveys from self-managing work team (SMWT) members in Belgium, Finland, the Philippines and the US, COL was also positively related to team members' job satisfaction and organizational commitment; and resistance to teams mediated the relationships between COL and both satisfaction and commitment, whereas resistance to self-management partially mediated the negative relationship between PD and commitment (Kirkman and Shapiro, 2001a). Gibson and Zellmer-Bruhn (2001) investigated teamwork metaphor use in interviews in France, Puerto Rico, the Philippines and the US in five multinational firms. PD was negatively related to using metaphors containing clear role content (e.g., family or military metaphors), and IND was negatively related to metaphors broad in scope (e.g., community metaphor).

\section{Research accomplishments}

Whereas Hofstede (1980a) was clear that his conceptualization and operationalization of cultural values was intended only for the country level, researchers have liberally adapted them for Type I studies at the individual level. Adaptation in this manner has both strengths and weaknesses. On the positive side, it has provided a new way to consider, describe and measure culture (Bond, 2002). Study variance that might have been attributed to other variables or explained with post hoc analyses has been used to derive and test theories about the cultural antecedents to individual outcomes in organizations. The framework demonstrates multimethod utility at the individual level of analysis, with Type I studies utilizing a variety of methods including experimental, managerial simulation, survey research, in-basket exercises, and scenarios. On the downside, there are clearly disconnects between the theoretical and methodological underpinning of Hofstede's (1980a) conceptualization and that of researchers working at the individual level. For example, findings that are incongruent with Hofstede (1980a), such as the studies that have shown that people in one country can be more individualistic and collectivistic, on average, than people from another country (Oyserman, 1993; Cocroft and Ting-Toomey, 1994; Gabrielidis et al., 1997; Oyserman et al., 2002), cannot be used to challenge his findings because of the conceptual differences inherent in the two levels of analysis (or perhaps methodological artifacts such as acquiescence bias). As we show in our general discussion, different empirical findings across levels (sometimes involving the same cultural values and outcomes) underscore the important theoretical differences between levels.

\section{Research challenges}

Of the 64 Type I studies at the individual level, only 12 included cultural values other than IND-COL, despite the fact that individuals are affected by a complex set of cultural values (Lytle et al., 1995; Kirkman and Shapiro, 1997). Indeed, all 12 studies that included cultural values in addition to (or besides) IND-COL found significant effects. Of the five studies that included both IND-COL and other cultural values simultaneously (e.g., Earley, 1986; Clugston et al., 2000; Mitchell et al., 2000; Kirkman and Shapiro, 2001a; Harpaz et al., 2002), all explained unique variance beyond IND-COL. Such consistent findings suggest that including cultural values other than IND-COL in the other 52 Type I studies would have led to important insights. Moreover, in the seven Type I studies that examined relationships involving IND-COL and country of origin simultaneously, five of the seven (e.g., Hui et al., 1991; Brett and Okumura, 1998; Gomez et al., 2000; Kirkman and Shapiro, 2001a; Tinsley and Brett, 2001) showed that country explained unique variance beyond IND-COL (only Tafarodi et al. (1999) and Tinsley (2001) showed full mediation effects). This 'hidden' variance could be explained by other cultural values besides IND-COL (Brett 
et al., 1997). Incorporating different Hofstedeinspired values (e.g., including UA with PD) or competing and complementary conceptualizations, such as Trompenaars' (1993) concept of universalism-particularism, which refers to the relative salience of rules (universals) or exceptions (particulars), is warranted. Reward allocation decisions could be affected by the extent to which subjects apply rules differently across recipients. Although not specifically discussed above, Kirkman and Shapiro (2001a) found that Kluckhohn and Strodtbeck's (1961) cultural value dimensions of doing-being orientation and free will-determinism explained unique variance beyond IND-COL and PD.

Further, even though researchers see clearer connections between IND-COL (compared with other values) and outcomes such as reward allocation, conflict, negotiation, and individual behavior in groups (Oyserman et al., 2002), the theoretical rationale is too limited. For example, in reward allocation and negotiation studies, the key role of status of the allocator, reward recipient, or negotiators (e.g., Leung and Lind, 1986; Leung, 1997) makes PD important, yet it is rarely assessed. Indeed, Fischer and Smith's (2003) meta-analysis showed that PD accounted for more significant cross-cultural differences in reward allocation than IND-COL (i.e., higher PD cultures allocate rewards using equity, rather than equality, rules). Thus including alternative cultural values is clearly warranted, and future reward allocation studies must at a minimum include PD. Unfortunately, when researchers include cultural values besides IND-COL, they tend to fall back on Hofstede's (1980a) country scores rather than direct, individual level measures (e.g., Bochner and Hesketh, 1994; Mitchell et al., 2000; Steensma et al., 2000a; Harpaz et al., 2002). We debate the validity of primary $v s$ secondary data in our discussion. Thus, much remains to be done on the direct measurement of PD, UA, MAS-FEM, and Confucian dynamism at the individual level (e.g., see the Type II individual level section for examples of the direct measurement of PD), and we recommend incorporating other value dimensions into this level of analysis.

Our review also demonstrated the importance of fine-grained models when conducting Type I studies at the individual level. Again, the reward allocation studies are useful for illustration. Although some researchers found associations between IND-COL and allocator preferences for equal or equitable distributions (Mann et al., 1985; Leung and Iwawaki, 1988; Hui et al., 1991), other studies found no relationship (McLean-Parks et al., 1999), or found that all subjects preferred equity distributions (Gomez et al., 2000). Including boundary conditions or moderating variables is the key to resolving such conflicting findings. For example, Tower et al. (1997) found that British and Russian allocators differed in their decision rule only when allocator performance was low rather than high. Similarly, C.C. Chen et al. (1998a, b) found that achievement motivation was significantly negatively related to differential allocation in both HK and the US when task interdependence was high; however, when task interdependence was low, the opposite was true for the US. Similarly, a series of studies showed that the ingroup-outgroup distinction played an important role for collectivists compared with individualists (Hui et al., 1991; Tower et al., 1997; Gomez et al., 2000). Such findings show that relationships involving IND-COL (and, by extension, other cultural values) exist only when certain contextual conditions are present. Leung (1997) drew a similar conclusion when reviewing several reward allocation studies, arguing that interactional goals and situational variables (i.e., the relationship between allocators and recipients and the role assumed by the allocator) interact with culture to affect the allocation rule adopted. Researchers should take these conditions into account to develop better-specified tests of existing theory involving moderators or mediators to explain the contingency relationships of cultural values at individual level.

\section{Type I studies of culture at the group/ organization level of analysis}

Type I studies at the group/organization level are fewer in number and more recent than individual level studies. Oetzel (1998) found that individualistic European-American groups had a greater number of conflicts, fewer cooperating tactics, and more competing tactics than collectivistic Japanese-American groups. In two studies also discussed in the individual level section, Pillai and Meindl (1998) found that COL was positively related to charismatic leadership emergence in a field study of 101 work groups; and Eby and Dobbins (1997) found that team collectivistic orientation was positively related to team cooperation, and team cooperation mediated the relationship between team collectivistic orientation and team performance in a study of 33 student teams. 
Kirkman and Shapiro (2001b) found that COL was negatively related to the level of team member resistance to the team-related aspects of SMWTs, and that resistance mediated the relationships COL had with team cooperation, empowerment, and productivity.

Elron (1997) assigned country scores (Hofstede, 1980a) to top management team (TMT) members to assess cultural heterogeneity in 121 subsidiaries in 34 countries. TMT cultural heterogeneity was positively related to TMT performance and conflict; however, conflict was negatively related to TMT performance. Cultural heterogeneity on both INDCOL and MAS-FEM was positively related to TMT performance; and heterogeneity in UA was positively related to conflict. Cox et al. (1991) assessed whether Asians, Blacks, and Hispanics were more collectivistic than Anglos based on the number of cooperative choices individuals made prior to group discussion. Ethnically diverse groups (i.e., those that were high, on average, in COL) behaved more cooperatively than all-Anglo groups (those that were low, on average, in COL), and that these differences tended to increase when situational cues favored cooperation. Of concern was the low reliability of their survey-based COL measure (a mixture of items from Triandis et al., 1986; Hui, 1988). Although Hofstede has offered a different set of dimensions for organizational, rather than national, culture (see Hofstede et al., 1990), two studies adapted his national culture framework for use at the organizational level. Morris et al. (1993) examined 84 manufacturing firms in the US and found a curvilinear relationship between IND-COL and entrepreneurial behavior such that at high levels of either IND or COL entrepreneurial behavior suffers. Morris et al. (1994) replicated the above findings using firms in South Africa, but their findings did not replicate in Portugal (possibly because of relatively high COL in Portugal).

\section{Research accomplishments}

Even though Hofstede (1980a) conceptualized and operationalized the value dimensions at the national level, it is not surprising that researchers have adapted the values for group and organization level studies as national cultures are 'groups,' and one might reasonably infer that cultural values are equally applicable to smaller groups such as teams and organizations. To justify aggregation, researchers commonly demonstrate more variation between groups than within using an analysis of variance (ANOVA) procedure, intraclass correlation coeffi- cient (ICC1) or within-and-between-analysis. Typically, there is evidence of high interrater agreement assessed using tests of within-group reliability $\left(r_{\mathrm{wg}}\right)$ or an ICC2 (e.g., Kirkman et al., 2001). From a pragmatic perspective, as organizations continue to use teams across subsidiaries of multinational firms, we see as very promising research that focuses on how cultural values affect teams and how cultural value diversity plays out at the group/ organization level.

\section{Research challenges}

Despite the huge increase in the use of teams in both the US and in organizations worldwide (Kirkman and Shapiro, 1997), we found a relative lack of attention to Type I studies at the group/organization level. However, conceptualizing and operationalizing cultural values at the group/organization level might be problematic for several reasons. First, researchers need to grapple with the question of whether culture is functionally isomorphic when moving from one level to the next (Chan, 1998). Simply put, does the meaning of a cultural value change from the individual to the group/organization level? Clearly, this question is just as relevant for those researchers who have adopted Hofstede's (1980a) country level measures for the individual level. This issue forms the basis for Hofstede's (1980a) warning about using his measures at the individual level of analysis; and our review shows that researchers studying the group and organizational levels are as curiously silent on this issue as those working at the individual level. Even if aggregation of individual data can be statistically justified, the importance of conceptually verifying that groups or organizations can indeed hold values that differentiate them from others in a national context cannot be overstated.

Second, cultural values are assumed to develop over time after repeated exposure to multiple facets of culture(s) (Hofstede, 1980a; Brett et al., 1997). It may be unreasonable to assume that because people share membership in a team, there will be more cultural value similarity within, rather than across, teams. Simply put, can working in teams (or organizations) alter deeply held, fundamental cultural values (Triandis, 2004)? Researchers must consider when it might be theoretically plausible to develop group or organizational level models involving cultural values before research is conducted, rather than assume similarity among individuals within teams. Similarity within teams or organizations requires accultural processes 
and/or attraction-similarity phenomenon, but these mechanisms are rarely explicitly argued or empirically tested. Further, perhaps the development of cultural values at the group/organization level depends upon team/organization tenure and task characteristics such as interdependence or cohesion.

In addition, whereas diversity studies have grown exponentially (Milliken and Martins, 1996), cultural value diversity has rarely been examined in favor of demographics (e.g., age, gender, ethnicity). This exclusion exists despite the finding that deep level diversity (i.e., differences due to values or beliefs) is more important for group functioning than surface level (i.e., demographic) diversity, especially over time (Harrison et al., 1998). Another intriguing question for researchers is what matters more, the mean level of cultural values in a group or group diversity on values? We found no studies that included both facets of cultural values at the group level. Further, as Supplementary Appendix A shows, group level theories were seldom used to build arguments for the impact of group level cultural values. More attention needs to be paid to the underlying dynamics connecting group level cultural values, group processes, and group effectiveness. Theories of collective cognition (e.g., Gibson, 2001), borrowing from social information processing, social cognition, or social identity research, might be effectively used.

Of the five cultural values, IND-COL was included most frequently in group/organization level studies, perhaps because of its close theoretical ties to group behavior. However, links between other cultural values and team processes and performance are equally plausible. For example, PD could be negatively related to willingness of a team to take autonomous action (Pillai and Meindl, 1998; Kirkman and Shapiro, 2001b). Masculine values (e.g., achievement, assertiveness, not caring for others) may affect cohesiveness (Hofstede, 1998). UA could affect group level phenomena such as risky shift or polarization (i.e., the tendency for groups to reach more risky or more extreme decisions than individuals). In addition, to assess cultural values at the group level, some studies used individual referents (e.g., 'I value my self-interest over my group interest' rather than 'My team members value their self-interest over their own interests') and then aggregated the items to the team level (e.g., Pillai and Meindl, 1998). Such a procedure violates commonly accepted practices for measuring group level constructs, aggregating only those items that have 'group' or 'team' referents (Chan, 1998). Thus, scholars should strive for level of analysis alignment between their theoretical foundation, hypotheses, operationalization of constructs, and analyses. If cultural values are assessed at the team level, then all items assessing cultural values should refer to the team, not individuals within the team, and all statistical analyses (e.g., reliability checks, factor analyses, regression) should be conducted using aggregated data.

\section{Type I studies of culture at the country level of analysis}

\section{Cultural distance (54)}

Most research at this level examined the impact of cultural distance on organizational and country level outcomes. Almost all studies used Kogut and Singh's (1988) index, which comprises the differences between a given (subsidiary) country's score on a cultural value and a (home) country's score, with differences summed across Hofstede's cultural values (see Shenkar (2001) and Harzing (2004) for recent critiques)]. Findings demonstrated that as the cultural distance between countries increased, the tendency to choose a joint venture (JV) over an acquisition increased (Kogut and Singh, 1988; Chang and Rosenzweig, 2001). However, Brouthers and Brouthers (2001) showed that investment risk moderated this relationship such that as risk increases, higher cultural distance is related to preferences for wholly owned entry modes rather than JVs. Also, as cultural distance increased, Japanese firms were more likely to choose greenfields (Anand and Delios, 1997) or wholly owned subsidiaries (Padmanabhan and Cho, 1996) over shared ownership; the tendency to choose licensing over JVs or wholly owned subsidiaries increased (Kim and Hwang, 1992); the tendency to choose a greenfield over an acquisition increased (Harzing, 2002); wholly owned subsidiaries were less preferred than either shared-equity ventures (Barkema and Vermeulen, 1998; Hennart and Larimo, 1998) or technology licensing (Arora and Fosfuri, 2000); the tendency to choose management-service contracts over franchising increased (Erramilli et al., 2002); a greater proportion of incentive-based compensation was used for subsidiary managers of host-country foreign affiliates (Roth and O'Donnell, 1996); equity JV partners were more likely to acquire an equal or majority (rather than minority) share (Pan, 1996; Erramilli et al., 1997); greater 
structural changes in alliance and contracts took place (Kashlak et al., 1998); firms engaged in less R\&D (Richards and De Carolis, 2003); and a greater number of TMTs departed from US companies acquired by foreign firms (Krug and Nigh, 1998).

In addition, as cultural distance increased, the amount of US foreign direct investment (FDI) decreased ( $\mathrm{Li}$ and Guisinger, 1992; Loree and Guisinger, 1995); shareholder wealth in those firms making cross-border acquisitions decreased (Datta and Puia, 1995); foreign venture longevity decreased (Barkema et al., 1996), especially when JVs or acquisitions were considered (Barkema et al., 1997); the level of embeddedness and integration between host companies and affiliates decreased (Hakanson and Nobel, 2001); the degree of personal attachment in international cooperative ventures decreased (Luo, 2001a), as did the frequency of expressive ties in organizational networks (Manev and Stevenson, 2001); and the level of CEO role conflict and ambiguity (Gong et al., 2001), international expansion performance (Luo and Peng, 1999), local responsiveness (Luo, 2001b), subsidiary return on assets (Luo and Park, 2001), the payoffs from JV partner buyouts (Reuer, 2001), IJV sales (Luo, 2002), and the likelihood of success of foreign-owned affiliates in the US (Li and Guisinger, 1991) all decreased. Increasing cultural distance from the US was negatively associated with entrepreneurial traits such as internal locus of control, moderate risk-taking, and high energy level at the country level (Thomas and Mueller, 2000). As the pre-entry international experience of firms increased, so did the likelihood of entering culturally dissimilar countries (Erramilli, 1991). Finally, compared with corporate cultural distance, national cultural distance better predicted stress, negative attitudes towards the merger, and actual cooperation (Weber et al., 1996).

Interestingly, others found that cultural distance did not affect initial or subsequent FDI decisions (Benito and Gripsrud, 1992); the type of cooperative arrangements of firms across borders (Pan and Tse, 1996); the choice between acquisitions, greenfields (Brouthers and Brouthers, 2000), alliance performance (Glaister and Buckley, 1999), firm performance (Gomez-Mejia and Palich, 1997), amount of FDI (Habib and Zurawicki, 2002), or abnormal return as a result of US international JV (IJV) announcement (Merchant and Schendel, 2000) or after FDIs are made (Kallunki et al., 2001). On the contrary, larger cultural distances were related to lower JV dissolution rates (Park and
Ungson, 1997), higher IJV (Pothukuchi et al., 2002), and cross-border acquisition performance (Morosini et al., 1998), decreased preference for greenfields (Nachum, 2003), and increased FDI into Mexico (Thomas and Grosse, 2001). Other research examined relationships using country scores on Hofstede's (1980a) cultural values while controlling for cultural distance. In these studies, firms preferred FDI over licensing (Shane, 1992, 1994) and sought majority ownership in foreign subsidiaries (Erramilli, 1996) in high PD countries, and UA was positively linked to majority ownership in foreign subsidiaries (Erramilli, 1996), a tendency to use JVs or greenfields over acquisitions (Kogut and Singh, 1988), and preferences for greenfield start-up ventures over acquisitions (Brouthers and Brouthers, 2000).

\section{Other country level studies (24)}

Beyond cultural distance, other Type I studies examined cultural values at the country level. Regarding HRM, Newman and Nollen (1996) examined the fit between national culture (using Hofstede's country scores) and management practices in 176 European and Asian work units located in 18 countries of a US-based multinational. When managers fitted their practices to a country's values, the units had higher return on assets and sales and, in some cases, higher bonuses than those with less fit. Findings held for all of the cultural values separately except UA. Using a variety of different worldwide compensation surveys and Hofstede's country scores, Schuler and Rogovsky (1998) found that IND was positively related to the use of payfor-performance and a focus on individual performance, social benefits such as child care and career breaks, and employee stock ownership plans (ESOPs). PD was negatively related to social benefits and ESOPs. UA was positively related to seniorityand skill-based pay plans and ESOPs and negatively related to a focus on individual performance. MAS was positively related to individual bonuses and commissions, career breaks, and maternity leave, and negatively related to flexible benefits and workplace childcare. From survey data of almost 1,000 companies in 20 countries, Ryan et al. (1999) found that, as UA increased, the number used and extent of verification methods in selection processes decreased (opposite to what was expected). The number of test types, extent of testing, number of interviews, use of a fixed list of interviews, and number of methods of auditing their selection processes all increased as UA increased. As the level 
of PD increased, the overall number of interviews used in selection and the extent of peer involvement in hiring increased while the use of peers as interviewers decreased.

Regarding innovation championing strategies, as UA increased, preferences for champions to work through organizational norms, rules and procedures increased. As PD increased, preferences for champions to focus on gaining the support of those in authority before other actions are taken rather than building a broad base of support increased; and as COL increased, preferences for champions to seek cross-functional support for innovation increased using survey data from 1,000 employees in 30 countries (Shane et al., 1995). In a study using over 4,000 survey responses in 68 countries, Shane (1995) found that lower levels of UA were associated with preferences for four innovation championing roles: the organizational maverick, the network facilitator, the transformational leader, and the organizational buffer. The greater legitimacy of these roles suggests that uncertainty acceptance may be linked to more innovative societies. Regarding leadership, PD was negatively related to leader communication, approachability, delegation, and team building; and UA was positively related to leader control and negatively to delegation and approachability using survey data of over 400 managers in a single multinational firm representing 39 different countries (Offerman and Hellmann, 1997). COL was positively associated with team-oriented leadership, and PD and UA were negatively associated with participative leadership in a sample of middle managers representing 54 countries at both societal and organizational levels (House et al., 1999). The authors note that all of the cultural value items were phrased using a 'should-be' orientation rather than a reflection of actual practices (p 217).

In studies of societal outcomes, using data from 18 countries common to both Hofstede (1980a) and the Chinese Values Survey (CVS; Chinese Culture Connection, 1987), Franke et al. (1991) found that Confucian dynamism was positively associated with economic growth between 1965-1980 and 1980-1987. IND was also positively related, but only in the first time period. IND was positively correlated with national wealth in a study of over 13,000 undergraduate students in 31 nations (Diener and Diener, 1995). PD, UA, and MAS were positively related to the level of corruption in over 40 countries (Husted, 1999). Diener et al. (1995) found that IND was strongly related to the subjective well-being of nations in a sample of undergraduate students in 55 nations. UA was negatively related to the use of professional accounting standards, and positively related to uniformity, conservatism, and secrecy in 29 countries (Salter and Niswander, 1995). MAS was positively related to uniformity and negatively related to conservatism, and IND was negatively related to secrecy. Ronkainen and Guerrero-Cusumano (2001) found that countries with higher COL, PD, and UA had higher rates of intellectual property rights violations in data from 50 countries (using Hofstede's (1980a) country scores).

Regarding alliance formation and entry modes (in studies that did not control for cultural distance), firms in high MAS cultures were less likely to pursue technology alliances than were firms in high FEM cultures; and firms in high IND cultures were less likely to pursue equity ties in their alliance formation in a sample of 494 manufacturing firms in Australia, Indonesia, Mexico, Norway, and Sweden (Steensma et al., 2000b). Firms from countries with large PD prefer subsidiary and equity JV entry modes whereas firms from countries high in UA prefer contract agreements and export entry modes, based on country scores from Hofstede (1980a), for 10,000 foreign entry activities into China between 1979 and 1998 (Pan and Tse, 2000). Firms from countries higher in UA preferred higher levels of equity ownership in 8,078 IJVs in China between 1979 and 1996 (Pan, 2002).

An interesting set of exchanges regarding relationships between national culture and role conflict, ambiguity, and overload took place in the Academy of Management Journal. Peterson et al. (1995) found that high PD and low IND were positively related to high levels of role overload and low levels of role ambiguity. In a challenge to Peterson et al.'s (1995) findings, Van de Vliert and Van Yperen (1996) found that average daytime temperature for a country's capital was positively related to role overload, and that PD scores were not significant once ambient temperature was entered. In a reply, Peterson and Smith (1997) added 11 new countries and replaced the capital city temperature with the temperature from the cities in which their data were actually collected. Results show that PD was more strongly associated with role overload than ambient temperature, and that the findings extended also to role ambiguity.

Finally, the remaining country level studies examined various relationships between national culture and outcomes. National culture was asso- 
ciated with whether a strategic case issue was seen as a crisis, as stimulating, as a threat, the future better if resolved, as difficult to resolve, quick action needed to resolve, one correct solution, and as seen as an opportunity based on survey data from 303 MBA students and executives in 16 countries that were grouped into five country clusters (Schneider and DeMeyer, 1991). Specifically, Latin Europeans were most likely to interpret the issue as a crisis and a threat. In a 25-country study, those highest in IND exhibited the lowest levels of information-seeking in individual networks (Zaheer and Zaheer, 1997). IND and PD were positively (and UA negatively) related to a country's systematic risk in its stock exchange in a 16-country study using Hofstede's (1980a) country scores (Riahi-Belkaoui, 1998). In a 23-country study, Smith et al. (1998) found that PD was negatively related to the frequency of outgroup disagreements; within collectivistic nations, disagreements were more frequently handled through reliance on rules rather than personal experience or training (the opposite was found for individualistic nations); and within low PD nations, ingroup disagreements were handled more frequently through reliance on subordinates whereas outgroup disagreements were more frequently handled through reliance on peers (compared with reliance on supervisors). Finally, Spector et al. (2001b), using survey data from over 5,000 managers in 24 countries, found that IND was positively related to both internal locus of control and job satisfaction.

\section{Research accomplishments}

The research above implies that decisions on how to expand internationally are influenced by how different participating countries are from each other on cultural value (country) scores. More generally, the findings reinforce Hofstede's (1980a) original contention that values are related to the aggregate management practices and beliefs of nations. The important findings regarding the fit between national culture and management practices (Newman and Nollen, 1996) demonstrated that being culturally sensitive pays (i.e., with higher returns on assets, sales, and higher bonuses). These 'fit' findings echo recent studies showing positive affects for empowerment in Mexico, Poland, and the US, but negative outcomes in India (Robert et al., 2000) and managerial reluctance to empower subordinates in high PD cultures (Aycan et al., 2000).

\section{Research challenges}

The most glaring need in Type I studies at the country level is to explain the many conflicting findings regarding cultural distance and decisions such as entry mode choice. As mentioned at the beginning of this section, Shenkar (2001) provided a scathing theoretical and methodological critique of the Kogut and Singh (1988) measure of cultural distance, and speculated that a number of 'hidden assumptions' could be at the root of the many conflicting findings with regard to FDI studies. One of these assumptions is the 'illusion of stability.' It is possible that, over time, Hofstede's (1980a) country scores used to create the cultural distance indices have lost predictive validity (we discuss this possibility further in the discussion). If no longer applicable, perhaps an alternative to the country score index is individual perceptions of differences (Shenkar (2001); see Kim and Hwang (1992) and Luo et al. (2001) for examples]. Another possibility [not considered by Shenkar (2001)] is that important moderators have been omitted. For example, Brouthers and Brouthers (2001) found that investment risk in the target market moderated the relationship between cultural distance and entry mode explaining the conflicting findings of previous studies. We urge researchers to continue to look for theoretically supported moderators of the cultural distance-outcome relationships. Other studies showed that examining 'distance' on each of the cultural values separately is important. For example, cultural distance on IND-COL and UA were negatively related to CEO role ambiguity (Shenkar and Zeira, 1992), UA and long-term orientation were negatively related to IJV survival (Barkema and Vermeulen, 1997), and IND was positively related to US research and development investments abroad (Jones and Teegen, 2001). Pothukuchi et al. (2002) found the positive relationship between overall cultural distance and IJV performance was explained primarily by cultural distance on MAS. Thus, findings for cultural distance can be explained by including specific cultural value dimensions independently (Shenkar, 2001). As Shenkar (2001) also noted, with regard to international expansion choices, perhaps UA is more important than the other cultural values thanks to its theoretical link with attitudes towards risk and formalization (e.g., see Barkema et al. (1997) for empirical tests of this possibility). Given all of these important findings, we take Shenkar's (2001) critique a step further (i.e., he recommended simply supplementing the Kogut and Singh (1988) 
measure with Confucian dynamism scores), we strongly encourage researchers to avoid further use of the overall cultural distance index.

\section{Type II studies of culture at the individual level of analysis}

Studies examining the moderating effects of culture at the individual level of analysis currently take three forms (from least to most analytically rigorous):

(1) testing whether people from various countries are significantly different on cultural values and then, on the basis of these differences, using country as a moderator;

(2) testing the moderating effects of culture using actual assessments of cultural values; or

(3) after testing the moderating effects of cultural values, determining whether or not country explains additional variance.

Clearly, the last approach is the most valuable, because researchers can show that cultural values account for country variation. Moderator effects imply that theories and practices for managing people need to be altered based on cultural contingencies. We organize these 24 moderating studies into the traditional management/psychology categories of negotiation, leadership, individual behavior relating to group processes, workrelated attitudes, motivation, and organizational justice.

\section{Negotiation (2)}

Gelfand and Realo (1999) conducted dyad negotiation experiments with Caucasian and Asian American undergraduate students in the US (Asians were significantly higher on COL) and undergraduate students in Estonia (who did not significantly differ on COL from US subjects). COL moderated the relationship between accountability and profit from negotiations such that in high accountability negotiations, the more collectivistic the dyad, the higher the level of willingness to concede, cooperative behavior, profit from the negotiation, and positive impressions of one's opponent. In low accountability negotiations, COL was negatively associated with these outcomes. $\mathrm{Ng}$ and Van Dyne (2001) found that HIND and HCOL moderated the relationship between minority influence and improvement in decision quality such that, in groups with minority influence, individuals higher rather than lower in HCOL were less likely to improve their decision quality. These results also held for those higher rather than lower in HIND; and influence targets higher rather than lower in VCOL also benefited more when the influence agent held a high status position in the group.

\section{Leadership (2)}

Jung and Avolio (1999) examined Asian and US American students working on a brainstorming task (Asians were significantly higher in COL than US Americans). Country moderated the relationship between leadership style and quantity of ideas such that Asian students generated more ideas working with a transformational leader than with a transactional leader (the opposite was true for US students). There were no statistical tests of INDCOL. A second study showed that IND-COL moderated the relationship between perceived uncertainty and the odds of using alliances such that the relationship was stronger when managers were collectivistic rather than individualistic (Dickson and Weaver, 1997).

Individual behavior relating to group processes (4) After confirming that managerial trainees in the PRC were significantly higher on COL than US participants, in a three-way interaction, Earley (1989) found that COL moderated the relationship between both accountability and shared responsibility and performance such that highly individualistic people performed poorest under conditions of high shared responsibility and low accountability, whereas highly collectivistic people performed better under conditions of high shared responsibility, regardless of accountability. Country did not explain any unique variance in performance beyond COL, and similar results were obtained when country was substituted for COL. In a followup experiment conducted with PRC, Israeli, and US managers (Earley, 1993), IND-COL moderated the relationship between group condition (i.e., working in an ingroup, outgroup or alone) and individual performance such that the performance of individualists who thought they were working in an ingroup or an outgroup was lower than the performance of individualists working alone; the performance of collectivists was lower in an individual or outgroup context than in an ingroup context; and participant ratings of self or group efficacy and their anticipated performance outcomes mediated the effects of IND-COL on performance. Y. Chen et al. (1998b) examined the effects of individual $v s$ collective primacy (referring to whether people give more weight to their personal 
interests than to their ingroup's interests when forced to choose between the two) and found that undergraduates from the PRC (who had more collective primacy orientation than those from the US) exhibited more ingroup favoritism when they performed well individually while their group performed poorly. Results were replicated substituting collective primacy for country and, in some cases, country no longer explained variance after collective primacy was entered. Wagner (1995) found that IND-COL moderated the relationships between both size and identifiability and cooperation such that size and identifiability have stronger effects on the cooperation of individualists than collectivists in a sample of US undergraduates.

\section{Work-related attitudes (5)}

In a sample of nearly 2,000 managers from 15 European and Canadian affiliates of a US multinational, Palich et al. (1995) did not find moderating effects for IND-COL, PD, UA, or MAS-FEM (using Hofstede's country scores) on the relationships between typical organizational commitment predictors (i.e., job scope, participative management, extrinsic rewards, and role clarity) and actual commitment. Similarly, in a study of European Commission employees representing 12 countries and using country scores, no moderating effects were found for the relationship between various components of commitment (i.e., affective, normative, and continuance) and intention to quit (Vandenberghe et al., 2001). Schaubroeck et al. (2000), after demonstrating that US bank tellers were significantly higher on IND and lower on COL than $\mathrm{HK}$ tellers, found that perceiving higher control mitigated the relationship between job demands and both psychological health symptoms and turnover intentions among US bank tellers reporting high job self-efficacy. In the HK sample, it was collective (not self-) efficacy that showed this pattern of effects. Similar results emerged when substituting IND-COL for country. After finding that southern Italians were more collectivistic than northern Italians, Martella and Maass (2000) found that region moderated the relationship between being unemployed and having lower life satisfaction, self-esteem, and happiness such that the relationships were stronger for northern rather than southern Italians (IND-COL, however, was never entered as a moderator). Finally, in a study discussed in the Type I individual level section, Thomas and $\mathrm{Au}$ (2002) found that HIND and VCOL moderated the relationships between both quality of job alternatives and job satisfaction and the behavioral responses of exit, voice, loyalty, and neglect. Specifically, horizontal individualists were more sensitive to quality of job alternatives when considering whether or not to exit; high levels of VCOL enhanced the relationship between quality of alternatives and exit; and quality of alternatives and voice were positively related at high, but not low, levels of HIND. For employees high in VCOL, job satisfaction was positively related to loyalty, but the relationship was stronger when quality of alternatives was high (opposite for employees low in VCOL).

\section{Motivation (5)}

After finding that US subjects were significantly lower on both COL and PD than Israelis, Erez and Earley (1987) found that country moderated the relationship between type of goal (assigned, representative, or participative) and performance such that the relationships between both representative and participative goal-setting and performance were stronger in Israel than the US. Identical findings were obtained when PD (but not COL) was substituted for country. In a sample of Mexican, Taiwanese and US managers working in Mexico and Taiwan, Dorfman and Howell (1988) found that cultural socialization (i.e., strong beliefs in the key cultural values of a society) moderated the relationship between directive leadership and both subordinate performance and satisfaction such that for individuals with high, rather than low, cultural socialization, directive leadership had stronger relationships to outcomes; but the effects of contingent reward leadership behaviors remained invariant regardless of the levels of cultural socialization. Earley (1994) found that country moderated the effects of type of training (individual- $v s$ group-focused) on self-efficacy and performance such that self-focused training had a stronger impact on self-efficacy and performance for US subjects whereas group-focused training had stronger effects for HK and PRC subjects. Within all three countries, individualists responded more favorably to individual-focused training than group-focused training, and collectivists showed the opposite pattern. Importantly, country of origin had no effect beyond COL. In a sample of MBA students in Canada in an experiment that manipulated empowerment, Eylon and Au (1999) found that PD (scores assigned based on language and country of origin) moderated the relationship between empowerment and performance such that 
for participants in the high PD group the disempowerment condition was associated with higher job performance than was the empowered or control condition; conversely, participants low in PD performed similarly across empowerment conditions. PD group (PD was never directly assessed) did not moderate the empowerment-job satisfaction relationship. Finally, Lam et al. (2002a) found that COL moderated the relationship between participative decision-making and individual performance, such that they were positively related for those high in IND (US employees were significantly higher on IND and lower on COL than HK employees). Importantly, country did not account for significant variance after IND had been entered.

\section{Organizational justice (6)}

In an experiment, Brockner et al. (2000) showed that when procedural fairness was high, outcome favorability had less of an impact on reactions to a decision in Taiwan than in Canada. Results were generally replicated substituting IND-COL (i.e., independent $v s$ interdependent self-construal) for country, and country failed to account for significant variance beyond IND-COL. Brockner et al. (2001) found that country moderated the relationship between voice and commitment such that participants were more likely to respond unfavorably (i.e., with lower levels of commitment) to low levels of voice when they were in lower (e.g., the US and Germany), rather than higher (e.g., the PRC and Mexico) PD countries. Similar to Brockner et al. (2000), results were replicated when PD was substituted for country, and country had no effects beyond PD. Also, similar results were obtained in the PRC for job satisfaction, intent to remain, and job performance. In contrast, Lind et al. (1997) found that the relationship between voice and perceptions of procedural justice was equally strong among students in Germany, HK, Japan, and the US (however, country was used as the moderator, not PD). Au et al. (2001), after confirming that Canadian undergraduates were significantly higher on IND than those from the PRC, found that country moderated the relationship between voice and taking responsibility such that when voice was offered by a service provider, Canadians were less likely to attribute the responsibility to themselves than were the Chinese (however, there were no tests of IND-COL). In a study of HK bank tellers, Lee et al. (2000b) found that PD moderated the relationships between both distributive and procedural justice and both trust in supervisor and psychological contract fulfillment such that the relationship between procedural justice and trust in supervisor was stronger for those lower, rather than higher, in PD; and the relationship between distributive justice and psychological contract fulfillment was stronger for those lower, rather than higher, in PD. Finally, Lam et al. (2002b) found that PD (but not IND) moderated the relationship between both distributive and procedural justice and work outcomes such that the relationships between the two types of justice and job satisfaction, performance, and absenteeism were more strongly positive for those lower, rather than higher in PD. HK bank tellers were significantly higher in PD than US tellers, but there were no moderating effects for country.

\section{Research accomplishments}

Like Type I research at the individual level, IND-COL was the most frequently examined value in Type II studies. Whether examining within-group or between-group behavior, collectivists were more likely to cooperate than were individualists, especially when accountability was high. Reinforcing the notion that collectivists place a higher value on ingroup, rather than outgroup, well-being, several studies demonstrated that the performance of collectivists was affected more by ingroup-outgroup status than individualists' performance. These findings echo those from the Type I section. There were, however, several key differences. First, the number of moderating studies is increasing rapidly (over half were published between 1999 and 2002), whereas the publishing rate for main effect studies remained stable. Second, of the six studies that included country and IND-COL in analyses simultaneously, all found that country no longer had a significant effect after IND-COL was entered. A seventh study (Brockner et al., 2001) found the same results with PD. Thus, when culture is a moderator, it is possible to specify the influence of a particularly potent dimension, and this dimension is likely to single-handedly account for differences across countries. This was not the case in main effects research, where a single cultural value very rarely explained all of the variation across countries.

\section{Research challenges}

Beyond IND-COL, PD was the only value examined as a moderator. We urge more Type II research on PD. Perhaps within-culture variation on PD explains why the expected relationship between 
participative goal-setting and both satisfaction and performance has not been consistently supported in the US. We urge more studies on employee participation (e.g., Lam et al., 2002a), utilizing all of the cultural value dimensions as possible moderators. It will be important for future research to examine the moderating effects of UA, for example, on receptivity to virtual work, and the moderating effect of Confucian dynamism, for example, on employee responses to downsizing and other economically focused initiatives. Finally, more research is needed to determine whether the lack of moderating effects for commitment (e.g., Palich et al., 1995) and turnover intentions (Vandenberghe et al., 2001) is due to the overall difficulty of detecting moderators (McClelland and Judd, 1993), using country scores instead of direct measures, or a high level of cultural invariance on these outcomes.

\section{Type II studies of culture at the group/ organization level of analysis}

A greater variety of cultural values was used in the group/organization level Type II studies relative to Type I. Regarding group efficacy, in a laboratory study of US and HK students and a field study of nursing teams in the US and Indonesia, Gibson (1999) found that COL moderated the relationship between group efficacy and group performance such that they were positively related when COL was high, but not low. Based on a simulation study of managers from England, France, Thailand and the US, Earley (1999) found that PD moderated the relationship between team members' personal estimates of group efficacy and collective judgments of group efficacy such that in high PD cultures, collective judgments of group efficacy were more strongly tied to higher, rather than lower, status group members' personal judgments. In low PD cultures, group members contributed comparably to group efficacy judgments. After finding that kibbutzim managers were higher in COL than urban managers in Israel, Erez and Somech (1996) found that the kibbutzim vs urban split moderated the relationship between both type of goal (individual $v s$ group) and incentive (individual $v s$ group) and group performance such that performance loss was less likely in kibbutzim than in urban groups. The highest level of performance was in kibbutzim groups with a group goal and group incentive (however, there were no direct tests of IND-COL). In a study discussed in the Type II individual level section, Lam et al. (2002a) found that IND-COL moderated the relationship between participative decision-making and group performance such that they were positively related for groups high, but not low, in COL and high participation efficacy. Importantly, country no longer accounted for significant effects beyond IND-COL.

By experimentally manipulating organizational cultures that were either individualistic or collectivistic and then assessing the cultural values of their US MBA subjects, Chatman and Barsade (1995) showed that individualistic-collectivistic organizational culture moderated the relationship between personal cooperation and cooperative behavior such that cooperative subjects in collectivistic cultures were more cooperative than individualistic subjects in the individualistic culture, individualistic subjects in a collectivistic culture, and collectivistic subjects in an individualistic culture. Individualists displayed similar cooperation regardless of organizational culture. Again using US MBAs, Chatman et al. (1998) found that individualistic-collectivistic organizational culture moderated the relationships between relational demography and social interaction, conflict, productivity, and creativity such that in collectivistic cultures demographic heterogeneity was positively related to communication; more conflict was found in individualistic than in collectivistic cultures, but collectivists viewed conflict as more beneficial; and as demographic similarity decreased, subjects in collectivistic cultures perceived themselves as more creative than those in individualistic cultures; similar people were more productive in individualistic than in collectivistic cultures, whereas dissimilar people were equally productive across the two cultures.

\section{Research accoplishments}

Experimental studies clearly show that COL contributes to collective efficacy, group performance, and cooperative behavior. Further, collectivistic organizational culture is related to conflict perceptions. Studies in this category demonstrated that group behavior is complex and often contextdependent (Earley and Gibson, 2002). Therefore, researchers need to continue to explore cultural moderators of group level relationships, with culture as an important contextual contingency condition. Further, in practice, as organizations become more global, they often do so using collaborative, team-based approaches (Kirkman and Shapiro, 1997). Practitioners struggle with the 
level of global integration and local responsiveness. The study of moderators at the group level can help inform these decisions. We would also argue that researchers examining group level Type I effects should emulate the research examining Type II effects reviewed in this section in terms of the wider variety of cultural values investigated (i.e., beyond the typical IND-COL or PD) and experimental methods.

\section{Research challenges}

As models are developed using moderators as key contingency factors, both theory development and advice to practitioners becomes increasingly narrow, applying to only a small population of employees (e.g., if a team with $X$ values is managed using $Y$ technique under $Z$ conditions, then we can expect success). Therefore, practical considerations and parsimony of models should be considered alongside the explanatory richness of moderator models at the group level. Similar to our criticism in the Type I group level section, we note that, with the exception of Earley (1999) and Gibson (1999), researchers often aggregated items with individual referents to the group level, violating a key requirement for assessing group level phenomena. We strongly encourage greater attention to such important methodological details to strengthen the robustness of research in this category.

\section{Type II studies of culture at the country level of analysis}

Few studies examined country level moderating effects, which seems curious for a framework that was conceived to explain country differences. In two studies discussed in the Type I country level section, Diener and Diener (1995) found that INDCOL moderated the relationship between both friendship satisfaction and life satisfaction, and between satisfaction with self and life satisfaction, such that the relationships were stronger in individualistic, rather than collectivistic, nations; and Steensma et al. (2000b) found that the relationship between perceived technological uncertainty and the use of technology alliances is stronger for firms in higher, rather than lower, UA countries and for firms in lower, rather than higher, MAS countries. In a 35-study meta-analysis, Robie et al. (1998) found that PD moderated the relationship between job level and job satisfaction such that it is weaker in lower PD countries. IND-COL moderated the relationship between marriage and life satisfaction such that it is stronger in collectivistic than individualistic countries (Diener et al., 2000). Spector et al. (2002) found that IND-COL did not moderate the relationship between locus of control and well-being (using the same data from Spector et al., 2001b). Finally, in a study of 295 IJVs in the PRC, cultural distance moderated the relationship between control and performance such that when cultural distance from the host country was higher, rather than lower, there was a weaker positive relationship between control and performance for foreign, but not Chinese, parents (Luo et al., 2001).

\section{Research accomplishments}

Type II country level studies show that Hofstede's cultural values have important effects on micro and macro level relationships across countries. We believe that this is true because country level phenomena are far removed (i.e., distal) antecedents for the relationships being examined. Yet some of the trends uncovered may be important factors to consider, particularly as economists begin to incorporate large, survey-based approaches to studying economic implications of macro-human resource phenomena at the country level (e.g., Gibbs and Levenson, 2002).

\section{Research challenges}

What is most glaring about the Type II country level studies is how few there are (five), compared with Type I studies at this level (78). Perhaps this is due, in part, to a trend initiated by Kogut and Singh (1988) to conceptualize country level cultural distance as a main effect, which may have led subsequent researchers to exclusively investigate such effects (in 54 studies), rather than moderating effects. As demonstrated by Luo et al. (2001) above, however, cultural distance did have interesting effects as a moderator. Thus, main effects researchers should at least control for the possibility.

\section{What has been learned, and where do we go from here?}

Perhaps the most pertinent question we should ask after conducting a comprehensive review is: should Hofstede's (1980a) cultural values framework continue to be used for cross-cultural research in the 21st century? Can a framework based on data collected in the 1960s and early 1970s continue to add value to the international management/ psychology fields? In general, we agree with Smith and Bond's $(1999,56)$ conclusion that large-scale 
studies published since Hofstede's (1980a) work (including Chinese Culture Connection, 1987; Schwartz, 1992, 1994; Trompenaars, 1993; Smith et al., 1996 as examples) 'have sustained and amplified [Hofstede's] conclusions rather than contradicted them.' Further, our review shows that researchers have used Hofstede's framework successfully to select countries that are culturally different in order to increase variance, and that most country differences predicted by Hofstede were supported. Thus, overall, Hofstede's values are clearly relevant for additional cross-cultural research. However, we temper our enthusiasm with several warnings for researchers. Our concluding section identifies theoretical and methodological implications and gaps in research that represent potential opportunities for future researchers.

\section{Theoretical implications}

\section{Similarities and differences in relationships across levels}

Although the small number of group/organization level studies constrained our detection of relationships across levels, we still found evidence for both cross-level similarities and differences. Regarding similarities, COL was associated with more cooperation and positive attitudes toward teams at the individual (Bennett, 1999; Eby et al., 2000; Kirkman and Shapiro, 2000, 2001a; Steensma et al., 2000a; Wade-Benzoni et al., 2002), group/organization (Chatman and Barsade, 1995; Eby and Dobbins, 1997; Kirkman and Shapiro, 2001b), and country levels (Schuler and Rogovsky, 1998; Steensma et al., 2000b). Similarly, IND was associated with increased conflict at the individual (Gabrielidis et al., 1997) and group/organization levels (Cox et al., 1991; Chatman et al., 1998; Oeztzel, 1998, and handling such conflict using personal experience or training rather than formal rules at the country level (Smith et al., 1998). This may help to explain why team efforts often fail in highly individualistic countries such as the US (Kirkman and Shapiro, 1997). COL was associated with preferences for, and the emergence of, non-directive leadership such as charismatic, participative, and team-oriented styles at the individual (Erez and Earley, 1987; Pillai and Meindl, 1998; Jung and Avolio, 1999), group/organization (Pillai and Meindl, 1998) and country levels (House et al., 1999). Cultural distance on UA had disruptive effects across levels, as it was associated with both increased conflict in TMTs (Elron, 1997) and the dissolution of IJVs at the country level (Barkema and Vermeulen, 1997). These similar findings across levels aside, we note that the substantiation of cross-level similarities is actually quite rare in the Hofstede-inspired research, not necessarily because they do not exist but because researchers seldom use a cross-level approach in a single study (exceptions included Eby and Dobbins, 1997; Pillai and Meindl, 1998; Lam et al., 2002a). As discussed below, we view such studies as promising, because they address multiple rival explanations for consistency across levels.

There was also evidence for differences across levels, even when considering the same values and outcomes. For example, at the individual level, COL was positively related to job satisfaction (Kirkman and Shapiro, 2001a), but at the country level the opposite was true (Spector et al., 2001b). At the group/organization level, IND-COL had a curvilinear relationship with entrepreneurship (Morris et al., 1993), but at the country level, increasing cultural distance from the US in terms of IND-COL (i.e., higher COL) was negatively related to entrepreneurial traits (Thomas and Mueller, 2000). At the individual level, cultural distance on COL was negatively related to group outcomes (receptiveness) (Thomas, 1999), but at the group/ organization level, heterogeneity on COL (a concept similar to cultural distance) was positively related to group outcomes (i.e., performance) (Elron, 1997). Differences were also found for associations among cultural values. Hofstede (1980a) reported a correlation of $-0.67(P<0.001)$ between IND-COL and PD in his original study of 40 countries and $-0.68(P<0.001)$ in his expanded study of 50 countries and three regions (Hofstede, 1983). Subsequent studies using data at the country level of analysis found similar results (e.g., Smith et al., 1998, $r=-0.78, P<0.001,23$ countries; Merritt, 2000, $r=-0.74, P<0.001,19$ countries). At the individual level, however, different correlations emerged (e.g., Birnbaum-More and Wong, 1995, $r=0.01$, n.s., for PRC, $r=0.03$, n.s., for HK; Dorfman and Howell, 1988, $r=0.17, P<0.01$ for China, $r=0.05$, n.s., for Mexico; Kirkman and Shapiro, 2001a, $r=-0.17$, n.s., for Belgium, $r=0.07$, n.s., for Finland, $r=0.06$, n.s., for Philippines, $r=-0.10$, n.s., for the US). These differences may be due, in part, to a major distinction in the conceptual underpinnings of IND-COL. That is, as mentioned earlier, there has been some debate that, at the country level, IND-COL is unipolar, but at the individual level it is bipolar (Oyserman et al., 2002). However, 
this is an empirical question that has yet to be satisfactorily resolved.

Given this inconsistency across levels, we expected to find a theoretical literature explaining the differences. On the contrary, we found the literature strangely silent, most likely because of the lack of research at multiple levels. We urge researchers to formulate theoretical rationales for the effects of cultural values across levels. Perhaps there are instances in which homology across levels is more likely than others. Researchers need to continue to explore relationships across levels in order to generate a complete nomological network for cultural values at multiple levels. We view as particularly promising carefully constructed and theoretically sound multi-level research programs informed by multi-level theory (see Klein and Kozlowski, 2000; Chen et al., 2004 for elaboration).

\section{Explore findings (within and) across countries}

Structural equivalence refers to the consistency of relationships among constructs of a model across countries (Brett et al., 1997). Similar to our criticism of the lack of research across levels, we also found that few researchers examined cultural value effects separately across countries. Exceptions include: Chen et al. (1998a), who found that COL was negatively related to reward differential in HK but not in the US; Gabrielidis et al. (1997), who found that in Mexico COL was positively correlated with collaboration (and not avoidance), whereas in the US COL was positively correlated with avoidance (and not collaboration); and Grimm et al. (1999), who found that IND was negatively related to agreeableness and conscientiousness in the US but not in the Philippines. Most studies do not analyze effects separately by country because researchers are interested primarily in how cultural values (not country) relate to outcome variables. When researchers do find different relationships by country, they tend to use post hoc rationalizations rather than theory to explain the differences. As there is likely to be within-country variation on all of the cultural values (Hofstede, 1980a), there may be compelling theoretical reasons why relationships between cultural values and outcomes differ depending on country. For example, Kirkman and Shapiro (2001a) theorized that the effects of cultural values on employee resistance to selfmanagement and teams would be stronger in the US than in the Philippines. The authors reasoned that employees would be less likely to resist company initiatives in countries with certain value constellations such as those high in COL (in which conformity norms would be high) and PD (in which employees would likely follow managerial directives without question). Using country as a moderator (which is similar to testing relationships within each country separately), Kirkman and Shapiro confirmed that cultural values were a much stronger predictor of resistance in the US than in the Philippines. As, methodologically, most researchers who collect data in multiple countries have the tools to conduct this analysis, the only barrier remaining is sufficient theory to justify why there might be differences in relationships across countries. To construct a more complete picture of the effects of cultural values, we urge researchers to pursue this under-researched area by developing coherent theory about different cultural value effects across countries at both the individual and group/organizational levels of analysis.

\section{Include theoretically relevant contextual moderators and mediators}

Type I studies at the individual level suggest that including contextual moderators explains seemingly contradictory relationships across different settings between, for example, culture and reward allocation. Specifically, including contextual moderators such as performance, status, task interdependence, and the ingroup-outgroup distinction helps explain why culture is associated with reward allocation behavior differently across studies (see Leung, 1997). Indeed, there may be theoretically meaningful contextual explanations for mixed findings that have yet to be probed. For example, Oyserman et al. (2002) argued that an over-reliance on student subjects (i.e., students tend to be higher in socioeconomic status than non-students, which is associated with higher IND) might have led researchers to underestimate cultural value differences among non-students. Thus, traditional demographic factors such as age, gender, and education (routinely collected in most research studies) should be investigated for their potential moderating effects across cultures (e.g., Farh et al., 1997). Likewise, only one of 54 cultural distance studies included cultural distance as a moderator rather than a main effect (Luo et al., 2001). We view this as an important theoretical advancement, and encourage researchers to include such moderators.

Mediators have also seldom been included, yet represent an opportunity for theoretical advancement. For example, Moorman and Blakely (1995) found that COL was positively related to OCB, 
whereas Van Dyne et al. (2000) found that organization-based self-esteem mediated the relationship. At the group level, COL was positively related to team performance, but cooperation (Eby and Dobbins, 1997) and resistance to teamwork (Kirkman and Shapiro, 2001b) mediated this relationship. Demography researchers have referred to the inability to explain why certain types of diversity relate to outcomes as a 'black box' (Lawrence, 1997). Our review shows that a parallel black box exists in international management and psychology research. Much work remains to be done to develop or select relevant theories to explain the underlying dynamics of cultural value-outcome linkages. The large number of studies that did not include theoretical linkages to explain the connection between values and organizational outcomes (see the frequency of the word 'none' in the 'Theories/models used' column in the Supplementary Appendices) underscores the lack of attention to these complex underlying dynamics.

\section{Explore new territory in terms of predictor and criterion variables - mind the gaps}

We were struck by the pattern of criterion variables across levels of analysis (see Table 3). Although some variables have little utility at the individual level (e.g., licensing, FDI) and others have less utility at group/organizational and country levels (e.g., personality), the trend in cross-cultural research has been to adapt Hofstede's (1980a) values for research on individual behavior and attitudes in spite of his objections (Hofstede, 2001). What has remained absent is attention to cultural values at the group/organization level. As Table 3 shows, many of the criterion variables have been investigated only at one level. For example, the relationship between culture and OCB was investigated only at the individual level (Moorman and Blakely, 1995; Van Dyne et al., 2000). Culture should have implications for OCB at the group/ organization level, given that norms guiding OCB often develop at these levels. One might also reasonably hypothesize that culture moderates the relationship between a number of inputs (e.g., leadership behaviors, work group resources, human resource practices) and OCB. Similarly, the relationship between culture and entrepreneurship, a notion rooted in individual behavior, was investigated only at the group/organization and country levels. Although culture might be related to the entrepreneurial behavior of individuals, again we found no empirical studies in our review. Finally, the relationship between culture and change was investigated only at the individual level of analysis, which seems very limited given that change management programs are typically targeted at organizations, strategic business units, divisions, or operations, rather than at specific individuals. An aberrant focus on the individual level of analysis misses rich information on how culture and cultural diversity in teams, groups and coalitions influence unit meaning-making attributions and acceptance or resistance to change management initiatives. In addition, most of the change studies were conducted only in the US, whereas change programs are often initiated by companies worldwide. Again, the lack of coherent research focused on key variables at multiple levels of analysis precludes us from synthesizing or distinguishing effects at the various levels.

Regarding predictors, Table 4 shows the number of times a cultural value was included in Types I and II studies at the three different levels of analysis. The group/organization level of analysis is clearly ripe for the inclusion of PD (only two studies at this level), UA (only one study), MAS-FEM (only one study), and Confucian dynamism (none at the group/organizational level). Before including cultural values in any study, the most important decision criterion is whether or not a particular value has theoretical relevance to the research question at a

Table 4 Number of inclusions of cultural values by type of effect and level of analysis

\begin{tabular}{lcccccc}
\hline & $\begin{array}{c}\text { Individualism- } \\
\text { collectivism }\end{array}$ & $\begin{array}{c}\text { Power } \\
\text { distance }\end{array}$ & $\begin{array}{c}\text { Uncertainty } \\
\text { avoidance }\end{array}$ & $\begin{array}{c}\text { Masculinity- } \\
\text { femininity }\end{array}$ & $\begin{array}{c}\text { Confucian } \\
\text { dynamism }\end{array}$ \\
\hline Main: individual & 58 & 11 & 8 & 8 & 3 \\
distance
\end{tabular}


particular level of analysis. We believe, given our previous discussion, that PD, UA, MAS-FEM, and Confucian dynamism are all theoretically relevant at the group/organization level. Future researchers should determine the particular questions of most pressing interest at this level.

In addition to levels of analysis opportunities, a review of Supplementary Appendices A and B and Table 3 also reveals gaps in type of effect. For example, organizational justice has been investigated only in Type II (moderator) studies. Given that procedural justice, in particular, has its theoretical roots in the group value model, which posits that fairness perceptions are based on one's relative standing to others, perhaps IND-COL or PD have Type I relationships with justice perceptions (Morris and Leung, 2000). Indeed, the correlation matrix of one Type II study showed that IND was positively, and PD negatively, related to both distributive and procedural justice for the HK sample, yet the authors did not make note of these main effects (Lam et al., 2002b). Interestingly, in the US, only PD and procedural justice were negatively related. Other areas ripe for future research include: the relationship between culture and reward allocation at the group/organizational level; decision-making or goal acceptance at the group/organization or country levels; role conflict/role ambiguity at the individual, or group/organization levels; and negotiation studies at the group/organization or country level of analysis. We urge cross-cultural researchers to investigate the theoretically useful opportunities evident in our review so that we may better understand the Types I and II relationships that culture has with organizational criteria.

\section{Examine theoretically relevant cultural value interaction effects}

Examining the interaction effects of cultural values is incredibly rare. We found only one study (Chen et al., 1997), which found an interaction effect for VCOL and HCOL. There are no compelling theoretical reasons to suspect that cultural values operate independently to influence outcomes (Gibson et al., forthcoming). On the contrary, there do exist theoretical rationales for why cultural values might interact. For example, none of the studies examined cultural values as they relate to group decisionmaking theories such as risky shift or polarization. It may be that shifts toward very low risk decisions occur in groups having high levels of both COL (i.e., higher group conformity) and UA (i.e., shunning risk). In fact, examining interactions among
IND and COL might provide insight into their complex (possibly independent) effects at the individual level. There may also be important interaction effects among different cultural values (e.g., IND and PD). We encourage researchers to explore these interactions.

\section{Methodological implications}

\section{Primary or secondary data}

We included studies that assessed cultural values through either primary (e.g., survey-based) or secondary (e.g., country scores, cultural distance indices) means. In support of secondary data, Morosini et al. (1998) argued that country scores avoid common method variance, retrospective evaluations and rationalizations that may accompany direct measures. However, assigning country level archival cultural value scores to individuals should concern researchers for several reasons. This approach involves using a single (country level) score, for IND-COL for example, assigned to individuals within each country. Yet studies have shown that people in one country can be more individualistic and collectivistic, on average, than people from another country (Oyserman, 1993; Cocroft and Ting-Toomey, 1994; Gabrielidis et al., 1997; Oyserman et al., 2002). Other studies failed to show differences that one would predict based on archival country scores (Leung and Iwawaki, 1988; Gabrielidis et al., 1997). As mentioned, it may be that IND and COL are bipolar rather than unipolar constructs at the individual level (Gelfand et al., 1996; Oyserman et al., 2002; Triandis, 2004). Thus, using country scores at the individual level could result in erroneous conclusions based on incorrect assignment of values. Second, cultural values can vary within, as well as between, countries (e.g., Bochner and Hesketh, 1994; Offerman and Hellmann, 1997). For example, Au (1999) found that intra-cultural variation on certain variables was greater than inter-cultural variation when comparing multiple countries. Using a single score for each country ignores this within-country variance. Third, researchers have shown significant cultural differences between regions or subcultures of a single nation (e.g., Hofstede, 1980a; Punnett and Withane, 1990; Selmer and DeLeon, 1996). Thus countries composed of two or more subcultures should preclude researchers from using country scores (McSweeney, 2002). Finally, using country scores derived from previous (decades old) research assumes uniform stability in values over time. Most 
cross-cultural researchers (including Hofstede) assume that cultures 'are relatively stable systems in equilibrium' (Brett et al., 1997, 79). However, empirically Ralston et al. (1999) compared three generations in the PRC and showed that Chinese managers are becoming more individualistic, less collectivistic, and lower in Confucian dynamism. In urging researchers to collect primary data, we do not suggest that this must take the form of self-report, survey-based methods. Researchers could conduct experiments in which cultural values are manipulated (see Leung and Su, 2004) or primed (Oyserman et al., 2002). Such studies could enhance internal validity and may help rule out country as an influence on individual outcomes (e.g., Morris et al., 2004). Research can capture cultural values in interviews using qualitative content analysis to characterize culture at the individual or group/organizational level. Gibson and Zellmer-Bruhn (2001) used this approach successfully in their examination of cultural variation in the use of teamwork metaphors.

\section{The importance of testing for cultural values as mediators}

Beyond the more general theoretical implications of including important mediators in cross-cultural research (discussed above), one methodological trend in our review is that studies that test specifically for cultural value mediation (showing that cultural values explain country effects) are analytically superior to those that test only for country or cultural value effects. Mediation tests allow researchers to support claims that country differences are due, in fact, to cultural values. Mediation techniques were used in both Type I (e.g., Hui et al., 1991; Brett and Okumura, 1998; Morris et al., 1998; Gibson, 1999; Tafarodi et al., 1999; Gomez et al., 2000; Kirkman and Shapiro, 2001a; Tinsley, 2001; Tinsley and Brett, 2001) and Type II studies (e.g., Y. Chen et al., 1998a, b; Earley, 1989, 1994; Brockner et al., 2000, 2001; Lam et al., 2002a). Rather than testing for the mediating effects of cultural values, some studies, after assessing country differences on cultural values, then used a country dummy variable, rather than cultural values, as a predictor variable (e.g., Mann et al., 1985; Tower et al., 1997; Arunachalam et al., 1998). Without mediation tests, researchers cannot attribute country differences to culture, although this has not stopped them from making such claims. For example, Tinsley and Pillutla (1998) found that HK Chinese subjects were higher on COL, and lower on IND, than US American subjects, but then used a country dummy variable in tests examining cultural differences. On the basis of significant effects for country, Tinsley and Pillutla (1998, 722) conclude: 'our results suggest that cultural values create an environment in which some negotiation strategies are selected to survive over others.' However, other cultural values (or country level factors) that might explain their country findings cannot be eliminated because these variables were not included in analyses (Lytle et al., 1995). An alternative conclusion for the Tinsley and Pillutla study is that HK and US negotiators differ, but the differences may be due to effects not measured in their study, a serious threat to internal validity (Leung and $\mathrm{Su}, 2004$ ). When researchers carry out studies in more than one culture, we cannot overstate the need to use mediation to support theoretical arguments that specific cultural values, rather than country differences in general, are responsible for the results obtained.

\section{Focus more attention on construct, measure, and sample equivalence}

Researchers often attempt to compare findings from their cross-cultural studies with previous studies. In doing so, they sometimes ignore methodological equivalence issues. For example, opposite findings emerged for the relationship between IND-COL and job satisfaction at the individual (Kirkman and Shapiro, 2001a) and country levels (Spector et al., 2001b). However, Kirkman and Shapiro used individual level measures developed by Maznevski et al. (2002), whereas Spector et al. relied on Hofstede's (1994) measures. Although the different findings may be due to missing moderators and contextual factors (Leung, 1997), we cannot completely rule out measurement equivalence as a competing explanation (Fischer and Smith, 2003). Indeed, after reviewing studies that assessed IND-COL in a variety of different ways, Oyserman et al. $(2002,43)$ conclude: 'at this time, it is impossible to tell the extent to which different cultural research methods... produce the same effects. If they do produce similar effects, it is unclear whether it is by the same process.' Thus, it behooves researchers to examine studies in detail to determine validity and reliability. It is also likely that the various outcome measures employed have differential validity in differing cultural contexts. Researchers are frequently constrained on this issue by their desire to compare effects across countries and cultures. Often, using locally valid measures in each country would prohibit researchers from 
making direct comparisons. However, in studies that do not attempt to make comparisons, we urge researchers to pay more attention to developing valid measures within the countries they study (see Farh et al., 1997; Gibson, 1999; Gibson and ZellmerBruhn, 2001 for examples of comprehensive measurement development techniques).

\section{Effect sizes}

We also thought it appropriate to briefly comment on the relative effect sizes produced by studies incorporating Hofstede's (1980a) cultural values (noting that some studies fail to include the information necessary to calculate these values). While we reviewed a great variety of studies demonstrating robust effects for the cultural values at the individual, group/organizational, and country levels of analysis, we also took note of a general trend of relatively low amounts of variance explained by the cultural values. For example, in a typical study of cultural values and organizational commitment, Palich et al. (1995) found that IND, UA, and MAS accounted for only $2.7 \%$ of the variance in employee commitment. Our observation echoes Oyserman et al.'s (2002) recent findings from their narrower meta-analysis of IND-COL demonstrating small effect sizes on psychological outcomes, especially for measures of IND. Beyond the measurement issues already discussed, the relatively low amount of variance explained by the cultural values in many studies underscores the existence of the many other forces besides culture that determine the behavior and attitudes of individuals in societies. One of the key questions raised by our review is not so much does culture matter (clearly, it does), but rather when does culture matter most? (See Gibson et al., forthcoming for a discussion.) We believe that examining a contingency view of the impact of cultural values is a fruitful area for future research.

The state of research on Hofstede's cultural values We have reviewed 180 articles and chapters that used Hofstede's (1980a) cultural values for empirical research in management and applied psychology fields. The findings of these studies are broad and impactful. However, despite this research, questions about cultural differences remain. In many areas, Hofstede-inspired research is fragmented, redundant, and overly reliant on certain levels of analysis and direction of effects. Moreover, researchers studying cultural values in organizations rarely cite research carried out in nonorganizational settings, and vice versa (Oyserman et al., 2002). This separation has led to redundancy and a lack of synergy. The more than 20 years that have passed since the publication of Culture's Consequences have produced an impressive quantity of research, but a comprehensive review suggests that so much more remains to be done. We encourage researchers to adopt our recommendations in order to more accurately and effectively utilize Hofstede's framework. We especially encourage researchers to thoroughly review our tables and appendices to identify valid research questions not yet asked at various levels of analysis. We strongly recommend refraining from producing yet another study at the same level of analysis and with the same measures already well investigated. Moreover, as one reviewer of this manuscript suggested, perhaps the time is right for a move beyond Culture's Consequences (or as the reviewer put it, a new 'paradigm' for cross-cultural research). Our review focused primarily on what has been learned from Hofstede-inspired research; it has said less about what his framework does not tell us. For example, what complementary cultural values exist beyond Hofstede's five dimensions, what cultural values might be unique to particular countries or regions (beyond Confucian dynamism), and what individual attributes (e.g., cognitions) might be more proximate to employee feelings or actions than cultural values (see Leung and Bond's (2004) discussion of social axioms)? We hope that our review helps researchers improve their use of Hofstede's framework, but we also hope that it motivates future researchers to look beyond this paradigm to break new ground with regard to crosscultural investigations. It is along this new frontier that the next generation of exciting cross-cultural discoveries will emerge.

\section{Acknowledgements}

We thank Nakiye Boyacigiller, Carolina Gomez, Geert Hofstede, Elizabeth Ravlin, Jack Viega, Kwok Leung, and two anonymous reviewers for helpful comments on previous versions of this manuscript.

\section{Notes}

${ }^{1}$ Exceptions are the research note prepared by Sondergaard (1994), which provides a brief overview of citations and replications of Hofstede's work, and Hofstede's (2001) own updating of his book.

${ }^{2}$ We thank an anonymous reviewer for this important point.

${ }^{3}$ Indicates the number of studies contained within each subject grouping. 


\section{References}

*Indicates an article included in the 180 publications analyzed for our review.

*Ali, A.J. (1993) 'Decision-making style, individualism, and attitudes toward risk of Arab executives', International Studies of Management and Organization 23(3): 53-73.

*Anakwe, U.P. Kessler, E.H. and Christensen, E.W. (1999) 'Distance learning and cultural diversity: potential users' perspective', International Journal of Organizational Analysis 7(3): 224-243.

*Anand, J. and Delios, A. (1997) 'Location specificity and the transferability of downstream assets to foreign subsidiaries', Journal of International Business Studies 28(3): 579-603.

*Arora, A. and Fosfuri, A. (2000) 'Wholly owned subsidiary versus technology licensing in the worldwide chemica industry', Journal of International Business Studies 31(4): 555-572.

*Arunachalam, V., Wall Jr, J.A. and Chan, C. (1998) 'Hong Kong versus US negotiations: effects of culture, alternatives, outcome scales, and mediation', Journal of Applied Social Psychology 28(14): 1219-1244.

*Au, K., Hui, M.K. and Leung, K. (2001) 'Who should be responsible? effects of voice and compensation on responsibility attribution, perceived justice, and post-complaint behaviors across cultures', International Journal of Conflict Management 12(4): 350-364.

Au, K.Y. (1999) 'Intra-Cultural variation: evidence and implications for international business', Journal of International Business Studies 30(4): 799-812.

Aycan, Z., Kanungo, R.N., Mendonca, M., Yu, K., Deller, J., Stahl, G. and Kurshid, A. (2000) 'Impact of culture on human resource management practices: a 10-country comparison' Applied Psychology: An International Review 49(1): 192-221.

*Barkema, H.G. and Vermeulen, F. (1997) 'What differences in the cultural backgrounds of partners are detrimental for international joint ventures?' Journal of International Business Studies 28(4): 845-864

*Barkema, H.G. and Vermeulen, F. (1998) 'International expansion through start-up or acquisition: a learning perspective' Academy of Management Journal 41(1): 7-26.

*Barkema, H.G., Bell, J.H.J. and Pennings, J.M. (1996) 'Foreign entry, cultural barriers, and learning', Strategic Management Journal 17(2): 151-166.

*Barkema, H.G., Shenkar, O., Vermeulen, F. and Bell, J. (1997) 'Working abroad, working with others: how firms learn to operate international joint ventures', Academy of Management lournal 40(2): 426-442.

*Benito, G.R.G. and Gripsrud, G. (1992) 'The expansion of foreign direct investments: discrete rational location choices or a cultural learning process?' Journal of International Business Studies 23(3): 461-476.

*Bennett III, R.H. (1999) 'The relative effects of situational practices and culturally influenced values/beliefs on work attitudes', International Journal of Commerce and Management 9(1/2): 84-102.

Birnbaum-More, P.H. and Wong, G.Y.Y. (1995) 'Acquisition of managerial values in the People's Republic of China and Hong Kong', Journal of Cross-Cultural Psychology 26(3): 255-275.

*Bochner, S. and Hesketh, B. (1994) 'Power distance, individualism/collectivism, and job-related attitudes in a culturally diverse work group', Journal of Cross-Cultural Psychology 25(2): 233-257.

Bond, M.H. (2002) 'Reclaiming the individual from Hofstede's ecological analysis - a 20-year odyssey: comment on Oyserman et al. (2002)', Psychological Bulletin 128(1): 73-77.

*Brett, J.M. and Okumura, T. (1998) 'Inter- and intracultural negotiation: US and Japanese negotiators', Academy of Management Journal 41(5): 495-510.

Brett, J.M., Tinsley, C.H., Janssens, M., Barsness, Z.I. and Lytle, A.L. (1997) 'New Approaches to the Study of Culture in I/O Psychology', in P.C. Earley and M. Erez (eds.), New Perspectives on International/Organizational Psychology, Jossey-Bass: San Francisco, pp: 75-129.

Brockner, J. (2005) 'Unpacking Country Effects: on the Need to Operationalize the Psychological Determinants of CrossNational Differences', in B.M. Staw and R.L. Sutton (eds.), Research in Organizational Behavior, vol. 25 JAl Press: Greenwich CT, pp: 335-369.

*Brockner, J., Chen, Y., Mannix, E.A., Leung, K. and Skarlicki, D. (2000) 'Culture and procedural fairness: when the effects of what you do depend on how you do it', Administrative Science Quarterly 45(2): 138-159.

*Brockner, J., Ackerman, G., Greenberg, J., Gelfand, M., Francesco, A., Chen, Z., Leung, K., Bierbrauer, G., Gomez, C.B., Kirkman, B.L. and Shapiro, D.L. (2001) 'Culture and procedural justice: the influence of power distance on reactions to voice', Journal of Experimental Social Psychology 37(4): 300-315.

*Brouthers, K.D. and Brouthers, L.E. (2000) 'Acquisition or Greenfield start-up? institutional, cultural, and transaction cost influences', Strategic Management Journal 21(1): 89-97.

*Brouthers, K.D. and Brouthers, L.E. (2001) 'Explaining the national cultural distance paradox', Journal of International Business Studies 32(1): 177-189.

*Cable, D.M. and Judge, T.A. (1994) 'Pay preferences and job search decisions: a person-organization fit perspective', Personnel Psychology 47(2): 317-348.

*Carpenter, S. and Radhakrishnan, P. (2000) 'Allocentrism and Idiocentrism as predictors of in-group perceptions: an individual difference extension of cultural patterns', Journal of Research in Personality 34(2): 262-268.

*Casimir, G. and Keats, D. (1996) 'The effects of work environment and in-group membership on the leadership preferences of Anglo-Australians and Chinese Australians', Journal of Cross-Cultural Psychology 27(4): 436-457.

Chan, D. (1998) 'Functional relations among constructs in the same content domain at different levels of analysis: a typology of composition models', Journal of Applied Psychology 83(2): 234-246.

*Chan, K.Y. and Drasgow, F. (2001) 'Toward a theory of individual differences and leadership: understanding the motivation to lead', Journal of Applied Psychology 86(3): 481-498.

*Chang, S.J. and Rosenzweig, P.M. (2001) 'The choice of entry mode in sequential foreign direct investment', Strategic Management Journal 22(8): 747-776.

*Chatman, J.A. and Barsade, S.G. (1995) 'Personality, organizational culture, and cooperation: evidence from a business simulation', Administrative Science Quarterly 40(3): 423-443.

*Chatman, J.A., Polzer, J.T., Barsade, S.G. and Neale, M.A. (1998) 'Being different yet feeling similar: the influence of demographic composition and organizational culture on work processes and outcomes', Administrative Science Quarterly 43(4): 749-780.

${ }^{*}$ Chen, C.C., Meindl, J.R. and Hunt, R.G. (1997) 'Testing the effects of vertical and horizontal collectivism: a study of reward allocation preferences in China', Journal of Cross-Cultural Psychology 28(1): 44-70.

*Chen, C.C., Meindl, J.R. and Hui, H. (1998a) 'Deciding on equity or parity: a test of situational, cultural, and individual factors', Journal of Organizational Behavior 19(2): 115-129.

Chen, G., Mathieu, J.E. and Bliese, P.D. (2004) 'A Framework for Conducting Multilevel Construct Validation', in F.J. Dansereau and F. Yamarino (eds.), Research in Multilevel Issues: Multilevel Issues in Organizational Behavior and Processes vol. 3, Elsevier: Oxford UK, pp: 273-303.

*Chen, Y., Brockner, J. and Katz, T. (1998b) 'Toward an explanation of cultural differences in in-group favoritism: the role of individual versus collective primacy', Journal of Personality and Social Psychology 75(6): 1490-1502.

Chinese Culture Connection (1987) 'Chinese values and the search for culture-free dimensions of culture', Journal of CrossCultural Psychology 18(2): 143-164. 
${ }^{*}$ Chiu, R.K. (1999) 'The role of affective dispositions in job satisfaction and work strain: comparing collectivist and individualist societies', International Journal of Psychology 34(1): 19-28.

*Clugston, M., Howell, J.P. and Dorfman, P.W. (2000) 'Does Cultural socialization predict multiple bases and foci of commitment?' Journal of Management 26(1): 5-30.

${ }^{*}$ Cocroft, B.K. and Ting-Toomey, S. (1994) 'Facework in Japan and the United States', International lournal of Intercultural Relations 18(4): 469-506.

${ }^{*}$ Cox, T.H., Lobel, S.A. and McLeod, P.L. (1991) 'Effects of ethnic group cultural differences on cooperative and competitive behavior on a group task', Academy of Management Journal 34(4): 827-847.

*Datta, D.K. and Puia, G. (1995) 'Cross-border acquisitions: an examination of the influence of relatedness and cultural fit on shareholder value creation in US acquiring firms', Management International Review 35(4): 337-359.

*Dickson, P.H. and Weaver, K.M. (1997) 'Environmental determinants and individual level moderators of alliance use', Academy of Management Journal 40(2): 404-425.

*Diener, E. and Diener, M. (1995) 'Cross-cultural correlates of life satisfaction and self-esteem', Journal of Personality and Social Psychology 68(4): 653-663.

*Diener, E., Diener, M. and Diener, C. (1995) 'Factors predicting the subjective well-being of nations', Journal of Personality and Social Psychology 69(5): 851-864.

*Diener, E., Gohm, C.L., Suh, E. and Oishi, S. (2000) 'Similarity of the relations between marital status and subjective wellbeing across cultures', Journal of Cross-Cultural Psychology 31(4): 419-436.

*Dorfman, P.W. and Howell, J.P. (1988) 'Dimensions of national culture and effective leadership patterns: Hofstede revisited', In: R.N. Farmer and E.G. McGoun (Eds.), Advances in International Comparative Management, Vol. 3 JAI Press: Greenwich, CT, pp. 127-150.

*Earley, P.C. (1986) 'Trust, perceived importance of praise and criticism, and work performance: an examination of feedback in the United States and England', Journal of Management 12(4): 457-473.

*Earley, P.C. (1989) 'Social loafing and collectivism: a comparison of the United States and the people's Republic of China', Administrative Science Quarterly 34(4): 565-581.

*Earley, P.C. (1993) 'East meets west meets Mideast: further explorations of collectivistic and individualistic work groups', Academy of Management Journal 36(2): 319-348.

*Earley, P.C. (1994) 'Self or group? cultural effects of training on self-efficacy and performance', Administrative Science Quarterly 39(1): 89-117.

*Earley, P.C. (1999) 'Playing follow the leader: status-determining traits in relation to collective efficacy across cultures', Organizational Behavior and Human Decision Processes 80(3): 192-212.

Earley, P.C. and Gibson, C.B. (1998) 'Taking stock in our progress on individualism-collectivism: 100 years of solidarity and community', Journal of Management 24(3): 265-304.

Earley, P.C. and Gibson, C.B. (2002) Multinational Teams: A New Perspective, Lawrence Earlbaum and Associates: Mahwah, NJ.

*Earley, P.C., Gibson, C.B. and Chen, C.C. (1999) "'How Did I Do?" Versus "How Did We Do?" cultural contrasts of performance feedback use and self-efficacy', Journal of CrossCultural Psychology 30(5): 594-619.

*Eby, L.T. and Dobbins, G.H. (1997) 'Collectivistic orientation in teams: an individual and group level analysis', Journal of Organizational Behavior 18(3): 275-295.

*Eby, L.T., Adams, D.M., Russell, J.E.A. and Gaby, S.H. (2000) 'Perceptions of organizational readiness for change: factors related to employees' reactions to the implementation of team-based selling', Human Relations 53(1): 419-442.
*Elron, E. (1997) 'Top management teams within multinational corporations: effects of cultural heterogeneity', Leadership Quarterly 8(4): 393-412.

*Erez, M. and Earley, P.C. (1987) 'Comparative analysis of goalsetting strategies across cultures', Journal of Applied Psychology 72(4): 658-665.

*Erez, M. and Somech, A. (1996) 'Is group productivity loss the rule or the exception? effects of culture and groupbased motivation', Academy of Management Journal 39(6): 1513-1537.

*Erramilli, M.K. (1991) 'The experience factor in foreign service market entry behavior of service firms', Journal of International Business Studies 22(3): 479-501.

*Erramilli, M.K. (1996) 'Nationality and subsidiary ownership patterns in multinational corporations', Journal of International Business Studies 27(2): 225-248.

*Erramilli, M.K., Agarwal, S. and Kim, S.S. (1997) 'Are firmspecific advantages location-specific too?' Journal of International Business Studies 28(4): 735-757.

*Erramilli, M.K., Agarwal, S. and Dev, C.S. (2002) 'Choice between non-equity entry modes: an organizational capability perspective', Journal of International Business Studies 33(2): 223-242.

Extejt, M.M. and Smith, J.E. (1990) 'The behavioral sciences and management: an evaluation of relevant journals', Journal of Management 16(3): 539-551.

*Eylon, D. and Au, K.Y. (1999) 'Exploring empowerment cross-cultural differences along the power distance dimension', International Journal of Intercultural Relations 23(3): 373-385.

Farh, J.L., Earley, P.C. and Lin, S.C. (1997) 'Impetus for action: a cultural analysis of justice and organizational citizenship behavior in Chinese society', Administrative Science Quarterly 42(3): 421-444.

*Feldman, D.C. and Bolino, M.C. (2000) 'Skill utilization of overseas interns: antecedents and consequences', Journal of International Management 6(1): 29-47.

Fischer, R. and Smith, P.B. (2003) 'Reward allocation and culture: a meta-analysis', Journal of Cross-Cultural Psychology 34(3): 251-268.

*Franke, R.H., Hofstede, G. and Bond, M.H. (1991) 'Cultural roots of economic performance: a research note', Strategic Management Journal 12(Special Issue): 165-173.

*Gabrielidis, C., Stephan, W.G., Ybarra, O., Dos Santos Pearson, V. and Villareal, L. (1997) 'Preferred styles of conflict resolution: Mexico and the US', Journal of Cross-Cultural Psychology 28(6): 661-677.

*Geletkanycz, M.A. (1997) 'The salience of 'culture's consequences': the effects of cultural values on top executive commitment to the status quo', Strategic Management Journal 18(8): 615-634.

*Gelfand, M.J. and Realo, A. (1999) 'Individualism-collectivism and accountability in intergroup negotiations', Journal of Applied Psychology 84(5): 721-736.

Gelfand, M.J., Triandis, H.C. and Chan, D.K. (1996) 'Individualism versus collectivism or versus authoritarianism?' European Journal of Social Psychology 26(3): 397-410.

Gibbs, M. and Levenson, A. (2002) 'The Economic Approach to Personnel Research', in S. Grossbard-Shechtman and C. Clague (eds.), The Expansion of Economics: Toward a More Inclusive Social Science, M.E. Sharpe: Armonk NY, pp: 99-139.

*Gibson, C.B. (1999) 'Do they do what they believe they can? group efficacy and group effectiveness across tasks and cultures', Academy of Management Journal 42(2): 138-152.

Gibson, C.B. (2001) 'From knowledge accumulation to accommodation: cycles of collective cognition in work groups', Journal of Organizational Behavior 22(2): 121-134.

*Gibson, C.B. and Zellmer-Bruhn, M. (2001) 'Metaphors and meaning: an intercultural analysis of the concept of teamwork', Administrative Science Quarterly 46(2): 274-303. 
Gibson, C.B., Maznevski, M.L. and Kirkman, B.L. (forthcoming) 'When Does Culture Matter?', in A.Y. Lewin (ed.), Emerging Issues in International Business, Macmillan Press: London.

*Glaister, K.W. and Buckley, P.J. (1999) 'Performance relationships in UK international alliances', Management International Review 39(2): 123-147.

*Gomez, C.B., Kirkman, B.L. and Shapiro, D.L. (2000) 'The impact of collectivism and ingroup/outgroup membership on the evaluation generosity of team members', Academy of Management Journal 43(6): 1097-1106.

Gomez-Mejia, L.R. and Balkin, D.B. (1992) 'Determinants of faculty pay: an agency theory perspective', Academy of Management Journal 35(5): 921-955.

*Gomez-Mejia, L.R. and Palich, L.E. (1997) 'Cultural diversity and the performance of multinational firms', Journal of International Business Studies 28(2): 309-335.

*Gong, Y., Shenkar, O., Luo, Y. and Nyaw, M. (2001) 'Role conflict and Ambiguity of CEOs in international joint ventures: a transaction cost perspective', Journal of Applied Psychology 86(4): 764-773.

*Grimm, S.D., Church, A.T., Katigbak, M.S. and Reyes, J.A.S. (1999) 'Self-described traits, values, and moods associated with individualism and collectivism: testing $\mathrm{I}-\mathrm{C}$ theory in an individualistic (US) and a collectivistic (Philippine) culture', Journal of Cross-Cultural Psychology 30(4): 466-500.

* Habib, M. and Zurawicki, L. (2002) 'Corruption and foreign direct investment', Journal of International Business Studies 33(2): 291-307.

*Hakanson, L. and Nobel, R. (2001) 'Organizational characteristics and reverse technology transfer', Management International Review 41(4): 395-420.

Hall, E. (1976) Beyond Culture, Anchor Press: Doubleday Garden City, NY.

*Harpaz, I., Honig, B. and Coetsier, P. (2002) 'A cross-cultural longitudinal analysis of the meaning of work and the socialization process of career starters', Journal of World Business 37(4): 230-244.

Harrison, D.A., Price, K.H. and Bell, M.P. (1998) 'Beyond relational demography: time and the effects of surface- and deep level diversity on work group cohesion', Academy of Management Journal 41(1): 96-107.

*Harzing, A.W.K. (2002) 'Acquisitions versus Greenfield investments: international strategy and management of entry modes', Strategic Management Journal 23: 211-227.

Harzing, A.W.K. (2004) 'The Role of Culture in Entry Mode Studies: from Negligence to Myopia?', in I. Cheng and M. Hitt (eds.), Advances in International Management, vol. 15 Elsevier: Amsterdam, pp: 75-127.

*Helgstrand, K.K. and Stuhlmacher, A.F. (1999) 'National culture: an influence on leader evaluations?' International Journal of Organizational Analysis 7(2): 153-168.

*Hennart, J. and Larimo, J. (1998) 'The impact of culture on the strategy of multinational enterprises: does national origin affect ownership decisions?' Journal of International Business Studies 29(3): 515-538.

Hofstede, G. (1980a) Culture's consequences: international differences in work related values, Sage: Beverly Hills, CA.

Hofstede, G. (1980b) 'Motivation, Leadership, and Organization: do American theories apply abroad?' Organizational Dynamics 9(1): 42-63.

Hofstede, G. (1983) 'Dimensions of National Culture in Fifty Countries and Three Regions', in J.B. Deregowski, S. Dziurawiec and R.C. Annis (eds.), Expiscations in CrossCultural Psychology, Swets and Zeitlinger: Lisse Netherlands, pp: $335-355$

Hofstede, G. (1994) Values Survey Module 1994 Manual, Institute for Research on Intercultural Cooperation: Maastrict, The Netherlands.

Hofstede, G. (1998) Masculinity and Femininity: The Taboo Dimensions of National Cultures, Sage: Thousand Oaks, CA.
Hofstede, G. (2001) Culture's Consequences: Comparing Values, Behaviors, Institutions, and Organizations Across Nations, Sage: Thousand Oaks, CA.

Hofstede, G. and Bond, M.H. (1988) 'The Confucius connection: from cultural roots to economic growth', Organizational Dynamics 16(4): 5-21.

Hofstede, G., Neuijen, B., Ohayv, D. and Sanders, G. (1990) 'Measuring organizational cultures: a qualitative and quantitative study across twenty cases', Administrative Science Quarterly 35(2): 286-316.

Hofstede, G., Bond, M.H. and Luk, C.L. (1993) 'Individual perceptions of organizational cultures: a methodological treatise on levels of analysis', Organization Studies 14(4): 483-503.

*House, R.J., Hanges, P.J., Ruiz-Quintanilla, S.A., Dorfman, P.W., Javidan, M., Dickson, M.W., Gupta, V. and Associates (1999) 'Cultural Influences on Leadership and Organizations: Project GLOBE', in W.H. Mobley, M.J. Gessner and V. Arnold (eds.), Advances in Global Leadership, Vol. 1 JAl Press: Greenwich CT, pp: 171-233.

*Hui, C.H. (1988) 'Measurement of individualism-collectivism', Journal of Research in Personality 22(1): 17-36.

*Hui, C.H. and Villareal, M.J. (1989) 'Individualism-Collectivism and Psychological Needs', Journal of Cross-Cultural Psychology 20(3): 310-323.

*Hui, C.H., Triandis, H.C. and Yee, C. (1991) 'Cultural differences in reward allocation: is collectivism the explanation?' British Journal of Social Psychology 30(2): 145-157.

*Husted, B.W. (1999) 'Wealth, culture, and corruption', Journal of International Business Studies 30(2): 339-360.

* James, K. (1993) 'Enhancing the perceived self-relevance of technology to influence attitudes and information retention', Journal of Applied Behavioral Science 29(1): 56-75.

Johnson, J.L. and Podsakoff, P.M. (1994) 'Journal influence in the field of management: an analysis using Salancik's index in a dependency network', Academy of Management Journal 37(5): 1392-1407.

*Jones, G.K. and Teegen, H.J. (2001) 'Global R\&D activity of US Mncs: does national culture affect investment decisions?' Multinational Business Review 9(2): 1-7.

*Jung, D.I. and Avolio, B.J. (1999) 'Effects of leadership style and followers' cultural orientation on performance in group and individual task conditions', Academy of Management Journal 42(2): 208-218.

*Kallunki, J.P., Larimo, J. and Pynnonen, S. (2001) 'Value creation in foreign direct investments', Management International Review 41(4): 357-376.

*Kashlak, R.J., Chandran, R. and Di Benedetto, C.A. (1998) 'Reciprocity in international business: a study of telecommunications alliances and contracts', Journal of International Business Studies 29(2): 281-304.

*Kim, W.C. and Hwang, P. (1992) 'Global strategy and multinationals' entry mode choice', Journal of International Business Studies 23(1): 29-54.

*Kirkman, B.L. and Shapiro, D.L. (1997) 'The impact of cultural values on employee resistance to teams: toward a model of Globalized self-managing work team effectiveness', Academy of Management Review 22(2): 730-757.

*Kirkman, B.L. and Shapiro, D.L. (2000) 'Understanding why team members won't share: an examination of factors related to employee receptivity to team-based rewards', Small Group Research 31(2): 175-209.

*Kirkman, B.L. and Shapiro, D.L. (2001a) 'The Impact of cultural values on job satisfaction and organizational commitment in self-managing work teams: the mediating role of employee resistance', Academy of Management Journal 44(3): 557-569.

*Kirkman, B.L. and Shapiro, D.L. (2001b) 'The impact of team members' cultural values on productivity, cooperation, and empowerment in self-managing work teams', Journal of CrossCultural Psychology 32(5): 597-617. 
Kirkman, B.L., Tesluk, P.E. and Rosen, B. (2001) 'Assessing the incremental validity of team consensus ratings over aggregation of individual level data in predicting team effectiveness', Personnel Psychology 54(3): 645-667.

Klein, K. and Kozlowski, S.W.J. (2000) Multilevel Theory, Research, and Methods in Organizations: Foundations, Extensions, and New Directions, Jossey-Bass: San Francisco.

Kluckhohn, F. and Strodtbeck, F.L. (1961) Variations in Value Orientations, Row, Peterson:Evanston, IL.

*Kogut, B. and Singh, H. (1988) 'The effect of national culture on the choice of entry mode', Journal of International Business Studies 19(3): 411-432.

*Krug, J.A. and Nigh, D. (1998) 'Top management departures in cross-border acquisitions: governance issues in an international context', Journal of International Management 4(4): 267-287.

*Kwan, V.S.Y., Bond, M.H. and Singelis, T.M. (1997) 'Pancultural explanations for life satisfaction: adding relationship harmony to self-esteem', Journal of Personality and Social Psychology 73(5): 1038-1051.

*Lam, S.S.K., Chen, X.P. and Schaubroeck, J. (2002a) 'Participative decision-making and employee performance in different cultures: the moderating effects of allocentrismidiocentrism and efficacy', Academy of Management Journal 45(4): 905-914.

*Lam, S.S.K., Schaubroeck, J. and Aryee, S. (2002b) 'Relationship between organizational justice and employee work outcomes: a cross-national study', Journal of Organizational Behavior 23(1): 1-18.

Lawrence, B.S. (1997) 'The black box of organizational demography', Organization Science 8(1): 1-22.

*Lee, A.Y., Aaker, J.L. and Gardner, W.L. (2000a) 'The pleasures and pains of distinct self-construals: the role of interdependence in regulatory focus', Journal of Personality and Social Psychology 78(6): 1122-1134.

*Lee, C., Pillutla, M. and Law, K.S. (2000b) 'Power-distance, gender, and organizational justice', Journal of Management 26(4): 685-704.

*Leung, K. (1987) 'Some determinants of reactions to procedural models for conflict resolution: a cross-national study', Journal of Personality and Social Psychology 53(5): 898-908.

*Leung, K. (1988) 'Some determinants of conflict avoidance', Journal of Cross-Cultural Psychology 19(1): 125-136.

Leung, K. (1997) 'Negotiation and Reward Allocations Across Cultures', in P.C. Earley and M. Erez (eds.), New Perspectives on International Industrial/Organizational Psychology, Jossey-Bass: San Francisco, pp: 640-675.

Leung, K. and Bond, M.H. (1989) 'On the empirical verification of dimensions for cross-cultural comparison', Journal of CrossCultural Psychology 20(2): 133-151.

Leung, K. and Bond, M.H. (2004) 'Social Axioms: a Model of Social Beliefs in Multi-Cultural Perspective', in M.P. Zanna (ed.), Advances in Experimental Social Psychology, vol. 36 Academic Press: New York.

*Leung, K. and Iwawaki, S. (1988) 'Cultural collectivism and distributive behavior', Journal of Cross-Cultural Psychology 19(1): 35-49.

Leung, K. and Lind, E.A. (1986) 'Procedural justice and culture: effects of culture, gender, and investigator status on procedural preferences', Journal of Personality and Social Psychology 50(6): 1134-1140.

Leung, K. and Su, S. (2004) 'Experimental Methods for Research on Culture and Management', in B.J. Punnett and O. Shenkar (eds.), Handbook for International Management Research, Blackwell: Oxford, pp: 68-98.

*Li, J. and Guisinger, S. (1991) 'Comparative business failures of foreign-controlled firms in the United States', Journal of International Business Studies 22(2): 209-224.

${ }^{*} \mathrm{Li}$, I. and Guisinger, S. (1992) 'The globalization of service multinationals in the "triad" regions: Japan, Western Europe, and North America', Journal of International Business Studies 23(4): 675-696.

*Lind, E.A., Tyler, T.R. and Huo, Y.J. (1997) 'Procedural context and culture: variation in the antecedents of procedural justice judgments', Journal of Personality and Social Psychology 73(4): 767-780.

*Loree, D.W. and Guisinger, S.E. (1995) 'Policy and non-policy determinants of US equity foreign direct investment', Journal of International Business Studies 26(2): 281-299.

*Luo, Y. (2001a) 'Antecedents and consequences of personal attachment in cross-cultural cooperative ventures', Administrative Science Quarterly 46(2): 177-201.

*Luo, Y. (2001b) 'Determinants of local responsiveness: perspectives from foreign subsidiaries in an emerging market', Journal of Management 27(4): 451-477.

* Luo, Y. (2002) 'Stimulating exchange in international joint ventures: an attachment-based view', Journal of International Business Studies 33(1): 169-181.

*Luo, Y. and Park, S.H. (2001) 'Strategic alignment and performance of market-seeking MNCs in China', Strategic Management Journal 22(2): 141-155.

*Luo, Y. and Peng, M.W. (1999) 'Learning to compete in a transition economy: experience, environment, and performance', Journal of International Business Studies 30(2): 269-296.

*Luo, Y., Shenkar, O. and Nyaw, M.K. (2001) 'A dual parent perspective on control and performance in international joint ventures: lessons from a developing economy', Journal of International Business Studies 32(1): 41-58.

Lytle, A.L., Brett, J.M., Barsness, Z.I., Tinsley, C.H. and Janssens, M. (1995) 'A Paradigm for Confirmatory Cross-Cultural Research in Organizational Behavior', in B. Staw and L. Cummings (eds.), Research in Organizational Behavior, vol. 17 JAI Press: Greenwich CT, pp: 167-214.

*Manev, I.M. and Stevenson, W.B. (2001) 'Nationality, cultural distance, and expatriate status: effects on the managerial network in a multinational enterprise', Journal of International Business Studies 32(2): 285-303.

*Mann, L., Radford, M. and Kanagawa, C. (1985) 'Cross-cultural differences in children's use of decision rules: a comparison between Japan and Australia', Journal of Personality and Social Psychology 49(6): 1557-1564.

*Martella, D. and Maass, A. (2000) 'Unemployment and life satisfaction: the moderating role of time structure and collectivism', Journal of Applied Social Psychology 30(5): 1095-1108.

Maznevski, M.L., Distefano, J.J., Gomez, C.B., Nooderhaven, N.G., and Wu P.C (2002) 'Cultural dimentions at the individual level of analysis: The cultural orientations framework', International Journal of Cross-Cultural Management 2(3): 275-295.

McClelland, G.H. and Judd, C.M. (1993) 'Statistical difficulties of detecting interactions and moderator effects', Psychological Bulletin 114(2): 376-390.

*McLean-Parks, J., Conlon, D.E., Ang, S. and Bontempo, R. (1999) 'The manager Giveth, the manager Taketh away: variation in distribution/recovery rules due to resource type and cultural orientation', Journal of Management 25(5): 723-757.

McSweeney, B. (2002) 'Hofstede's model of national cultural differences and their consequences: a triumph of faith - a failure of analysis', Human Relations 55(1): 89-118.

*Merchant, H. and Schendel, D. (2000) 'How do international joint ventures create shareholder value?' Strategic Management Journal 21(7): 723-737.

Merritt, A. (2000) 'Culture in the cockpit: do Hofstede's dimensions replicate?' Journal of Cross-Cultural Psychology 31(3): 283-301.

Milliken, F.J. and Martins, L.L. (1996) 'Searching for common threads: understanding the multiple effects of diversity in organizational groups', Academy of Management Review 21(2): 402-433. 
*Mitchell, R.K., Smith, B., Seawright, K.W. and Morse, E.A (2000) 'Cross-cultural cognitions and the venture creation decision', Academy of Management Journal 43(5): 974-993.

*Moorman, R.H. and Blakely, G.L. (1995) 'Individualism-collectivism as an individual difference predictor of organizational citizenship behavior', Journal of Organizational Behavior 16(2): 127-142.

*Morosini, P., Shane, S. and Singh, H. (1998) 'National cultural distance and cross-border acquisition performance', Journal of International Business Studies 29(1): 137-158.

*Morris, M.H., Avila, R.A. and Allen, J.W. (1993) 'Individualism and the modern corporation: implications for innovation and entrepreneurship', Journal of Management 19(3): 595-612.

*Morris, M.H., Davis, D.L. and Allen, J.W. (1994) 'Fostering corporate entrepreneurship: cross-cultural comparisons of the importance of individualism versus collectivism', Journal of International Business Studies 25(1): 65-89.

Morris, M.W. and Leung, K. (2000) 'Justice for all? progress in research on cultural variation in the psychology of distributive and procedural justice', Applied Psychology: An International Review 49(1): 100-132.

*Morris, M.W., Williams, K.Y., Leung, K., Larrick, R., Mendoza, M.T., Bhatnagar, D., Li, J., Kondo, M., Luo, J. and Hu, J. (1998) 'Conflict management style: accounting for cross-national differences', Journal of International Business Studies 29(4): 729-748.

Morris, M.W., Leung, K. and lyengar, S.S. (2004) 'Person perception in the heat of conflict: negative trait attributions affect procedural preferences and account for situational and cultural differences', Asian Journal of Social Psychology 7(2): 127-147.

*Nachum, L. (2003) 'Does nationality of ownership make any difference and, if so, under what circumstances? Professional service MNEs in global competition', Journal of International Management 9(1): 1-32.

*Newman, K.L. and Nollen, S.D. (1996) 'Culture and congruence: the fit between management practices and national culture', Journal of International Business Studies 27(4): 753-779.

${ }^{*} \mathrm{Ng}$, K.Y. and Van Dyne, L. (2001) 'Individualism-collectivism as a boundary condition for effectiveness of minority influence in decision making', Organizational Behavior and Human Decision Processes 84(2): 198-225.

*Nooteboom, B., Berger, H. and Noorderhaven, N.G. (1997) 'Effects of trust and governance on relational risk', Academy of Management lournal 40(2): 308-338.

*Oetzel, J.G. (1998) 'Culturally homogeneous and heterogeneous groups: explaining communication processes through individualism-collectivism and self-construal', International Journal of Intercultural Relations 22(2): 135-161.

*Offerman, L.R. and Hellmann, P.S. (1997) 'Culture's consequences for leadership behavior', Journal of Cross-Cultural Psychology 28(3): 342-351.

*Oyserman, D. (1993) 'The lens of personhood: viewing the self and others in a multicultural society', Journal of Personality and Social Psychology 65(5): 993-1009.

*Oyserman, D., Sakamoto, I. and Lauffer, A. (1998) 'Cultural accommodation: hybridity and the framing of social obligation', Journal of Personality and Social Psychology 74(6): 1606-1618.

Oyserman, D., Coon, H.M. and Kemmelmeier, M. (2002) 'Rethinking individualism and collectivism: evaluation of theoretical assumptions and meta-analyses', Psychological Bulletin 128(1): 3-72.

*Ozawa, K., Crosby, M. and Crosby, F. (1996) 'Individualism and resistance to affirmative action: a comparison of Japanese and American samples', Journal of Applied Social Psychology 26(13) 1138-1152.

*Padmanabhan, P. and Cho, K.R. (1996) 'Ownership strategy for a foreign affiliate: an empirical investigation of Japanese firms', Management International Review 36(1): 45-65.
*Palich, L.E., Hom, P.W. and Griffeth, R.W. (1995) 'Managing in the international context: testing the cultural generality of sources of commitment to multinational enterprises', Journal of Management 21(4): 671-690.

*Pan, Y. (1996) 'Influences on foreign equity ownership level in joint ventures in China', Journal of International Business Studies 27(1): 1-26.

*Pan, Y. (2002) 'Equity ownership in international joint ventures: the impact of source country factors', Journal of International Business Studies 33(2): 375-384.

*Pan, Y. and Tse, D.K. (1996) 'Cooperative strategies between foreign firms in an overseas country', Journal of International Business Studies 27(5): 929-946.

* Pan, Y. and Tse, D.K. (2000) 'The hierarchical model of market entry modes', Journal of International Business Studies 31(4): 535-554.

*Park, S.H. and Ungson, G.R. (1997) 'The effect of national culture, organizational complementarity, and economic motivation on joint venture dissolution', Academy of Management Journal 40(2): 279-307.

* Pearson, V.M.S. and Stephan, W.G. (1998) 'Preferences for styles of negotiation: a comparison of Brazil and the US', International Journal of Intercultural Relations 22(1): 67-83.

*Peterson, M.F. and Smith, P.B. (1997) 'Does national culture or ambient temperature explain cross-national differences in role stress? no sweat!', Academy of Management Journal 40(4): 930-946.

*Peterson, M.F. et al. (1995) 'Role conflict, ambiguity, and overload: a 21 -nation study', Academy of Management Journal 38(2): 429-452.

*Pillai, R. and Meindl, J.R. (1998) 'Context and charisma: a "Meso" level examination of the relationship of organic structure, collectivism, and crisis to charismatic leadership', Journal of Management 24(5): 643-671.

*Pothukuchi, V., Damanpour, F., Choi, J., Chen, C.C. and Park, S.H. (2002) 'National and organizational culture differences and international joint venture performance', Journal of International Business Studies 33(2): 243-265.

*Probst, T.M., Carnevale, P.J. and Triandis, H.C. (1999) 'Cultural values in intergroup and single-group social dilemmas', Organizational Behavior and Human Decision Processes 77(3): 171-191.

Punnett, B.J. and Withane, S. (1990) 'Hofstede's value survey module: to embrace or abandon?', In: R.N. Farmer and E.G. McGoun (Eds.), Advances in International Comparative Management, Vol. 5, JAI Press: Greenwich, CT, pp. 69-89.

Ralston, D.A., Egri, C.P., Stewart, S., Terpstra, R.H. and Kaicheng, Y. (1999) 'Doing business in the 21st century with the new generation of Chinese managers: a study of generational shifts in work values in China', Journal of International Business Studies 30(2): 415-428.

*Ramamoorthy, N. and Carroll, S.J. (1998) 'Individualism/ collectivism orientations and reactions toward alternative human resource management practices', Human Relations 51(5): 571-588

* Reuer, J.J. (2001) 'From hybrids to hierarchies: shareholder wealth effects of joint venture partner buyouts', Strategic Management Journal 22(1): 27-44.

*Riahi-Belkaoui, A. (1998) 'Cultural determinism and systematic risk of global stock exchanges', International Journal of Commerce and Management 8(3/4): 102-108.

*Richards, M. and De Carolis, D.M. (2003) 'Joint venture research and development activity: an analysis of the international biotechnology industry', Journal of International Management 9(1): 33-49.

*Robert, C., Probst, T.M., Martocchio, J.J., Drasgow, F. and Lawler, J.j. (2000) 'Empowerment and continuous improvement in the United States, Mexico, Poland, and India: predicting fit on the basis of dimensions of power distance and individualism', Journal of Applied Psychology 85(5): 643-658. 
*Robie, C., Ryan, A.M., Schnieder, R.A., Parra, L.F. and Smith, P.C. (1998) 'The relation between job level and job satisfaction', Group and Organization Management 23(4): 470-495.

Ronen, S. and Shenkar, O. (1985) 'Clustering countries on attitudinal dimensions: a review and synthesis', Academy of Management Review 10(3): 435-454.

*Ronkainen, I.A. and Guerrero-Cusumano, J. (2001) 'Correlates of intellectual property violation', Multinational Business Review 9(1): 59-65.

*Roth, K. and O'Donnell, S. (1996) 'Foreign subsidiary compensation strategy: an agency theory perspective', Academy of Management Journal 39(3): 678-703.

*Ryan, A.M., McFarland, L., Baron, H. and Page, R. (1999) 'An international look at selection practices: nation and culture as explanations for variability in practice', Personnel Psychology 52(2): 359-391.

*Salter, S.B. and Niswander, F. (1995) 'Cultural influence on the development of accounting systems internationally: a test of gray's Theory', Journal of International Business Studies 26(2): 379-397.

*Satterwhite, R.C., Feldman, J.M., Catrambone, R. and Dai, L.Y. (2000) 'Culture and perceptions of self-other similarity', International Journal of Psychology 35(6): 287-293.

*Schaubroeck, J., Lam, S.S.K. and Xie, J.L. (2000) 'Collective efficacy versus self-efficacy in coping responses to stressors and control: a cross-cultural study', Journal of Applied Psychology 85(4): 512-525.

*Schneider, S.C. and DeMeyer, A. (1991) 'Interpreting and responding to strategic issues: the impact of national culture', Strategic Management Journal 12(4): 307-320.

*Schuler, R.S. and Rogovsky, N. (1998) 'Understanding compensation practice variations across firms: the impact of national culture', Journal of International Business Studies 29(1): 159-177.

Schwartz, S.H. (1992) 'Universals in the Content and Structure of Values: Theoretical Advances and Empirical Tests in 20 Countries', in M.P. Zana (ed.), Advances in Experimental Social Psychology, vol. 25 Academic Press:New York, pp: 1-65.

Schwartz, S.H. (1994) 'Cultural dimensions of values: towards an understanding of national differences', in U. Kim, H.C. Triandis, C. Kagitcibasi, S.C. Choi and G. Yoon (eds.), Individualism and Collectivism: Theoretical and Methodological Issues, Sage: Thousand Oaks, CA, pp: 85-119.

Selmer, J. and De Leon, C. (1996) 'Parent cultural control through organizational acculturation: HCN employees learning new work values in foreign business subsidiaries', Journal of Organizational Behavior 17(1): 557-572.

Shackleton, V.J. and Ali, A.H. (1990) 'Work-related values of managers: a test of Hofstede's model', Journal of Cross-Cultural Psychology 21(1): 109-118.

*Shane, S. (1992) 'The effect of cultural differences in perceptions of transaction costs on national differences in the preference for licensing', Management International Review 32(4): 295-311.

*Shane, S. (1994) 'The effect of national culture on the choice between licensing and direct foreign investment', Strategic Management Journal 15(8): 627-642.

*Shane, S. (1995) 'Uncertainty avoidance and the preference for innovation championing roles', Journal of International Business Studies 26(1): 47-68.

* Shane, S., Venkataraman, S. and MacMillan, I. (1995) 'Cultural differences in innovation championing strategies', Journal of Management 21(5): 931-952.

Shenkar, O. (2001) 'Cultural distance revisited: towards a more rigorous conceptualization and measurement of cultural differences', Journal of International Business Studies 32(3): 519-535.

*Shenkar, O. and Zeira, Y. (1992) 'Role conflict and role ambiguity of chief executive officers in international joint ventures', Journal of International Business Studies 23(1): $55-75$.
Singelis, T.M., Triandis, H.C., Bhawuk, D.S. and Gelfand, M. (1995) 'Horizontal and vertical dimensions of individualism and collectivism: a theoretical and measurement refinement', Cross-Cultural Research 29(3): 240-275.

Sivakumar, K. and Nakata, C. (2001) 'The stampede toward Hofstede's framework: avoiding the sample design pit in crosscultural research', Journal of International Business Studies 32(3): 555-574

Smith, P.B. (2002) 'Culture's consequences: something old and something new', Human Relations 55(1): 119-135.

Smith, P.B. and Bond, M.H. (1999) Social Psychology Across Cultures, 2nd edn, Allyn \& Bacon: Boston.

Smith, P.B., Dugan, S. and Trompenaars, F. (1996) 'National culture and the values of organizational employees', Journal of Cross-Cultural Psychology 27(2): 231-264.

* Smith, P.B., Dugan, S., Peterson, M.F. and Leung, K. (1998) 'Individualism-collectivism and the handling of disagreement: a 23 country study', International Journal of Intercultural Relations 22(3): 351-367.

Sondergaard, M. (1994) 'Hofstede's consequences: a study of reviews, citations, and replications', Organization Studies 15(3): 447-456.

Spector, P.E., Cooper, C.L., Sparks, K. (2001a) 'An international study of the psychometric properties of the Hofstede values survey module 1994: a comparison of individual and country/ province level results', Applied Psychology: An International Review 50(2): 269-281.

*Spector, P.E., et al. (2001b) 'Do national levels of individualism and internal locus of control relate to well-being: an ecological level international study', Journal of Organizational Behavior 22(8): 815-832.

* Spector, P.E., et al. (2002) 'Locus of control and well-being at work: how generalizable are western findings?' Academy of Management Journal 45(2): 453-466.

*Steensma, H.K., Marino, L. and Weaver, K.M. (2000a) 'Attitudes toward cooperative strategies: a cross-cultural analysis of entrepreneurs', Journal of International Business Studies 31(4): 591-609.

*Steensma, H.K., Marino, L., Weaver, K.M. and Dickson, P.H. (2000b) 'The influence of national culture on the formation of technology alliances by entrepreneurial firms', Academy of Management Journal 43(5): 951-973.

*Tafarodi, R.W., Lang, J.M. and Smith, A.J. (1999) 'Self-esteem and the cultural trade-off: evidence for the role of individualism-collectivism', Journal of Cross-Cultural Psychology 30(5): 620-640.

Tahai, A. and Meyer, M.L. (1999) 'A revealed preference study of management journals' direct influences', Strategic Management Journal 20(3): 279-296.

*Thomas, A.S. and Mueller, S.L. (2000) 'A case for comparative entrepreneurship: assessing the relevance of culture', Journal of International Business Studies 31(2): 287-301.

*Thomas, D.C. (1999) 'Cultural diversity and work group effectiveness: an experimental study', Journal of Cross-Cultural Psychology 30(2): 242-263.

*Thomas, D.C. and Au, K. (2002) 'The effect of cultural differences on behavioral responses to low job satisfaction', Journal of International Business Studies 33(2): 309-326.

*Thomas, D.E. and Grosse, R. (2001) 'Country-of-origin determinants of foreign direct investment in an emerging market: the case of Mexico', Journal of International Management 7(1): $59-79$.

*Tinsley, C.H. (2001) 'How negotiators get to yes: predicting the constellation of strategies used across cultures to negotiate conflict', Journal of Applied Psychology 86(4): 583-593.

*Tinsley, C.H. and Brett, J.M. (2001) 'Managing workplace conflict in the United States and Hong Kong', Organizational Behavior and Human Decision Processes 85(2): 360-381.

*Tinsley, C.H. and Pillutla, M.M. (1998) 'Negotiating in the United States and Hong Kong', Journal of International Business Studies 29(4): 711-728. 
*Tower, R.K., Kelly, C. and Richards, A. (1997) 'Individualism, collectivism and reward allocation: a cross-cultural study in Russia and Britain', British Journal of Social Psychology 36(3): 331-345.

Triandis, H.C. (1995) Individualism and Collectivism, Boulder, CO: Westview Press.

Triandis, H.C. (2004) 'The many dimensions of culture', Academy of Management Executive 18(1): 88-93.

Triandis, H.C., et al. (1986) 'The measurement of the ethnic aspects of individualism and collectivism across cultures', Australian Journal of Psychology 38(3): 257-267.

*Triandis, H.C., Bontempo, R., Villareal, M.J., Asai, M. and Lucca, N. (1988) 'Individualism and collectivism: cross-cultural perspectives on self-ingroup relationships', Journal of Personality and Social Psychology 54(2): 323-338.

Trompenaars, F. (1993) Riding the Waves of Culture: Understanding Diversity in Global Business, Irwin: Chicago, IL.

*Vandenberghe, C., Stinglhamber, F., Bentein, K. and Delhaise, T. (2001) 'An examination of the cross-cultural validity of a multinational model of commitment in Europe', Journal of Cross-Cultural Psychology 32(3): 322-347.

*Van de Vliert, E. and Van Yperen, N.W. (1996) 'Why crossnational differences in role overload? don't overlook ambient temperature!', Academy of Management Journal 39(4): 986-1004.

*Van Dyne, L., Vandewalle, D., Kostova, T., Latham, M.E. and Cummings, L.L. (2000) 'Collectivism, propensity to trust and self-esteem as predictors of organizational citizenship in a nonwork setting', Journal of Organizational Behavior 21(1): 3-23.

*Wade-Benzoni, K.A., Okumura, T., Brett, J., Moore, D.A., Tenbrunsel, A.E. and Bazerman, M.H. (2002) 'Cognitions and behavior in asymmetric social dilemmas: a comparison of two cultures', Journal of Applied Psychology 87(1): 87-95.

*Wagner III, J.A. (1995) 'Studies of individualism-collectivism: effects on cooperation in groups', Academy of Management Journal 38(3): 152-172.

Wagner III, J.A and Moch, M.H. (1986) 'Individualism-collectivism: Concept and measure', Group \& Organization Studies 11(3): 280-304.

*Weber, Y., Shenkar, O. and Raveh, A. (1996) 'National and corporate cultural fit in mergers/acquisitions: an exploratory study', Management Science 42(8): 1215-1227.

*Wojciszke, B. (1997) 'Parallels between competence-versus morality-related traits and individualistic versus collectivistic values', European Journal of Social Psychology 27(3): 245-256.

*Yamaguchi, S., Kuhlman, D.M. and Sugimori, S. (1995) 'Personality correlates of allocentric tendencies in individualist and collectivist cultures', Journal of Cross-Cultural Psychology 26(6): 658-672.
*Zaheer, S. and Zaheer, A. (1997) 'Country effects on information seeking in global electronic networks', Journal of International Business Studies 28(1): 77-100.

\section{About the authors}

Bradley L. Kirkman is Associate Professor of Management and Mays Research Fellow in the Mays Business School at Texas A\&M University. $\mathrm{He}$ received his $\mathrm{PhD}$ in Organizational Behavior from the Kenan-Flagler Business School at the University of North Carolina at Chapel Hill. His research interests include international management, virtual teams, and work team effectiveness. He is an Associate Editor of the Academy of Management Journal.

Kevin B. Lowe is Associate Professor of Business Administration in the Joseph M. Bryan School of Business and Economics at the University of North Carolina Greensboro. He received his $\mathrm{PhD}$ in Organizational Behavior from the Chapman Graduate School of Business at Florida International University. His research interests include crosscultural management and leadership.

Cristina B. Gibson is Associate Professor of Organization and Strategy in the Paul Merage School of Business at the University of California-Irvine, where she received her $\mathrm{PhD}$ in Organizational Behavior. Her research interests include the development and testing of theories of collective cognition, focusing on the manner in which culture, organizational structures and policies, and technology serve as key influences on collective cognitive processes.

Supplementary information accompanies the paper on the Journal of International Business Studies website (www.palgrave-journals.com/jibs). 